FEDERAL RESERVE BANK OF SAN FRANCISCO

WORKING PAPER SERIES

\title{
Demographics and Real Interest Rates: Inspecting the Mechanism
}

\author{
Carlos Carvalho \\ PUC-Rio \\ Andrea Ferrero \\ University of Oxford \\ Fernanda Nechio \\ Federal Reserve Bank of San Francisco \\ March 2016 \\ Working Paper 2016-05 \\ http://www.frbsf.org/economic-research/publications/working-papers/wp2016-05.pdf
}

\section{Suggested citation:}

Carvalho, Carlos, Andrea Ferrero, Fernanda Nechio. 2016. "Demographics and Real Interest Rates: Inspecting the Mechanism.” Federal Reserve Bank of San Francisco Working Paper 2016-05. http://www.frbsf.org/economic-research/publications/working-papers/wp2016-05.pdf

The views in this paper are solely the responsibility of the authors and should not be interpreted as reflecting the views of the Federal Reserve Bank of San Francisco or the Board of Governors of the Federal Reserve System. 


\title{
Demographics and Real Interest Rates:
}

\author{
Inspecting the Mechanism*
}

\author{
Carlos Carvalho \\ PUC-Rio
}

\author{
Andrea Ferrero \\ University of Oxford
}

Fernanda Nechio

FRB San Francisco

April 23, 2016

\begin{abstract}
The demographic transition can affect the equilibrium real interest rate through three channels. An increase in longevity - or expectations thereof - puts downward pressure on the real interest rate, as agents build up their savings in anticipation of a longer retirement period. A reduction in the population growth rate has two counteracting effects. On the one hand, capital per-worker rises, thus inducing lower real interest rates through a reduction in the marginal product of capital. On the other hand, the decline in population growth eventually leads to a higher dependency ratio (the fraction of retirees to workers). Because retirees save less than workers, this compositional effect lowers the aggregate savings rate and pushes real rates up. We calibrate a tractable life-cycle model to capture salient features of the demographic transition in developed economies, and find that its overall effect is a reduction of the equilibrium interest rate by at least one and a half percentage points between 1990 and 2014. Demographic trends have important implications for the conduct of monetary policy, especially in light of the zero lower bound on nominal interest rates. Other policies can offset the negative effects of the demographic transition on real rates with different degrees of success.
\end{abstract}

JEL codes: E52, E58, J11

Keywords: Life expectancy, population growth, demographic transition, real interest rate, monetary policy, zero lower bound, Secular Stagnation

*This paper was prepared for the 2015 Conference on "Post-Crisis Slump," held at the European Commission in Brussels on October 1-2, 2015. For comments and suggestions, we thank our discussant Michael Krause and seminar participants at the Conference, the Bundesbank, Nova School of Business, University of Copenhagen, HECER, Bank of Finland, University of Essex, University of Warwick, and University of Southampton. The views expressed in this paper do not necessarily reflect the position of the Federal Reserve Bank of San Francisco or of the Federal Reserve System. Eric Hsu provided excellent research assistance. Emails: cvianac@econ.puc-rio.br, andrea.ferrero@economics.ox.ac.uk, fernanda.nechio@sf.frb.org. 


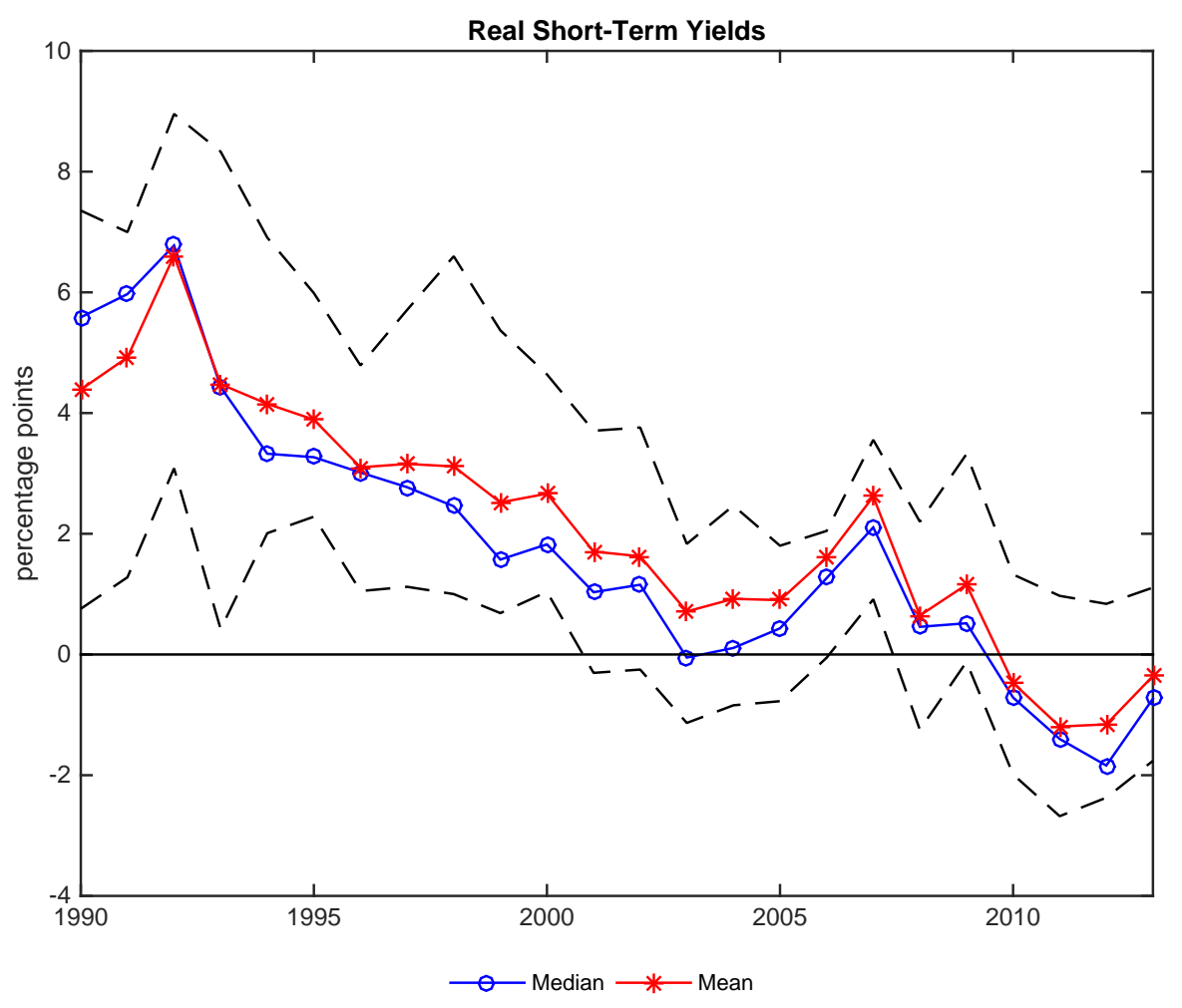

Figure 1: Median (blue line with circles) and mean (red line with stars) ex-post real short-term interest rates, calculated as yields on short-term government securities with maturity less than one year minus realized CPI inflation. The sample consists of Belgium, Germany, Denmark, Finland, France, Greece, Iceland, Ireland, Italy, Japan, Netherlands, Norway, Portugal, Spain, Sweden, United Kingdom, United States. The dashed lines indicate the 90-10 range across countries.

\section{Introduction}

Since the Global Financial Crisis (GFC), real interest rates in many developed economies have been in negative territory, as nominal interest rates have hovered around zero and inflation rates, although quite low for historical standards, have remained positive and roughly stable (in most countries, at least on average). This observation naturally brings forth the implication that accommodative monetary policies (both conventional and unconventional) that were put in place in response to the GFC are the reason behind ultra-low real rates. If this were indeed the case, this phenomenon would be over as soon as central banks start to normalize monetary policy. Yet, a longer-term perspective immediately reveals a different picture. Real interest rates have been trending down for more than two decades across many countries (Figure 1). These low-frequency movements suggest that forces other than accommodative monetary policies must be at play.

Demographic trends are a natural candidate explanation for low and declining real interest rates. The world is undergoing a dramatic demographic transition. In most advanced economies people tend to live longer. In Japan, the U.S. and Western Europe, life expectancy at birth has increased by about 10 years between 1960 and 2010 ( left panel of Figure 2), and new generations have continued to expect 

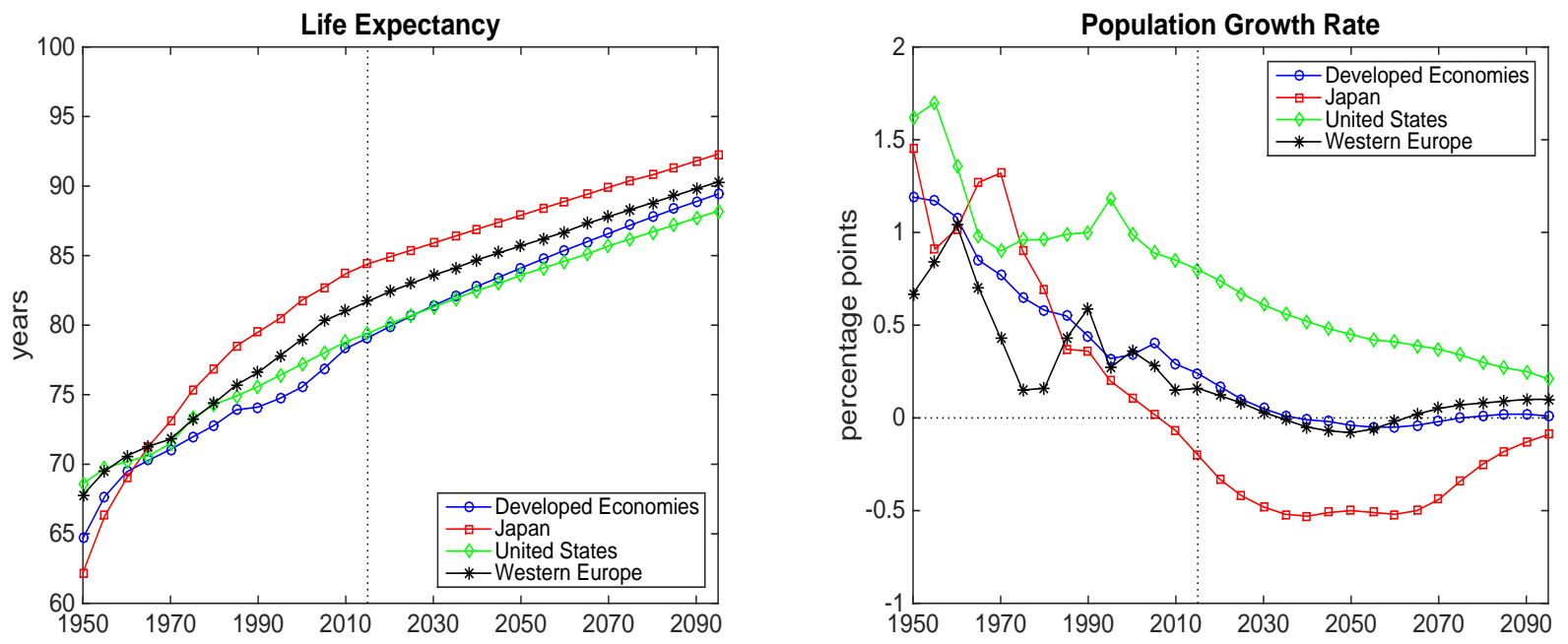

Figure 2: Left panel: Years of life expectancy at birth. Right panel: Population growth rate. Sample: Developed Economies (Northern America, Europe, Japan, Australia, New Zealand; blue line with circles), Japan (red line with squares), United States (green line with diamonds), Western Europe (black line with stars). Source: United Nations World Population Prospects (2015 Revision).

longevity to increase. At the same time, immigration notwithstanding, population growth rates are decreasing at a fast pace, and in some cases (e.g. Japan) becoming negative (right panel of Figure 2). The combination of the population growth slowdown and the increase in longevity implies a notable increase in the dependency ratio - i.e. the ratio between people 65 years and older and people 15 to 64 years old (Figure 3). The consequences of this demographic transition are far reaching and have important macroeconomic, public finance, and political economy repercussions. ${ }^{1}$

In this paper, we focus on the consequences of the demographic transition for real interest rates. We illustrate three channels through which such transition can affect the equilibrium real interest rate using a tractable life-cycle model. For a given retirement age, an increase in life expectancy lengthens the retirement period and generates additional incentives to save throughout the life cycle. ${ }^{2}$ This effect tends to be stronger if agents believe that public pension systems will not be able to bear the additional burden generated by an aging population. Therefore, an increase in longevity-and expectations thereof - tends to put downward pressure on the real interest rate, as agents build up their savings in anticipation of a longer retirement period.

A drop in the growth rate of the population produces two opposite effects on real interest rates. On the one hand, lower population growth leads to a higher capital-labor ratio, which depresses the marginal product of capital. This "supply effect" is very much akin to a permanent slowdown in productivity growth, pushing down real interest rates. On the other hand, however, lower population growth eventually drives up the dependency ratio. Because retirees have a lower marginal propensity

\footnotetext{
${ }^{1}$ See Nishimura (2011) for an excellent discussion of the possible connections between the demographic transition and the recent global financial crisis.

${ }^{2}$ Acemoglu and Johnson (2007) study the effects of increases in life expectancy on economic growth. Ferrero (2010) focuses on the implication of differentials in life expectancy among advanced economies for international capital flows.
} 


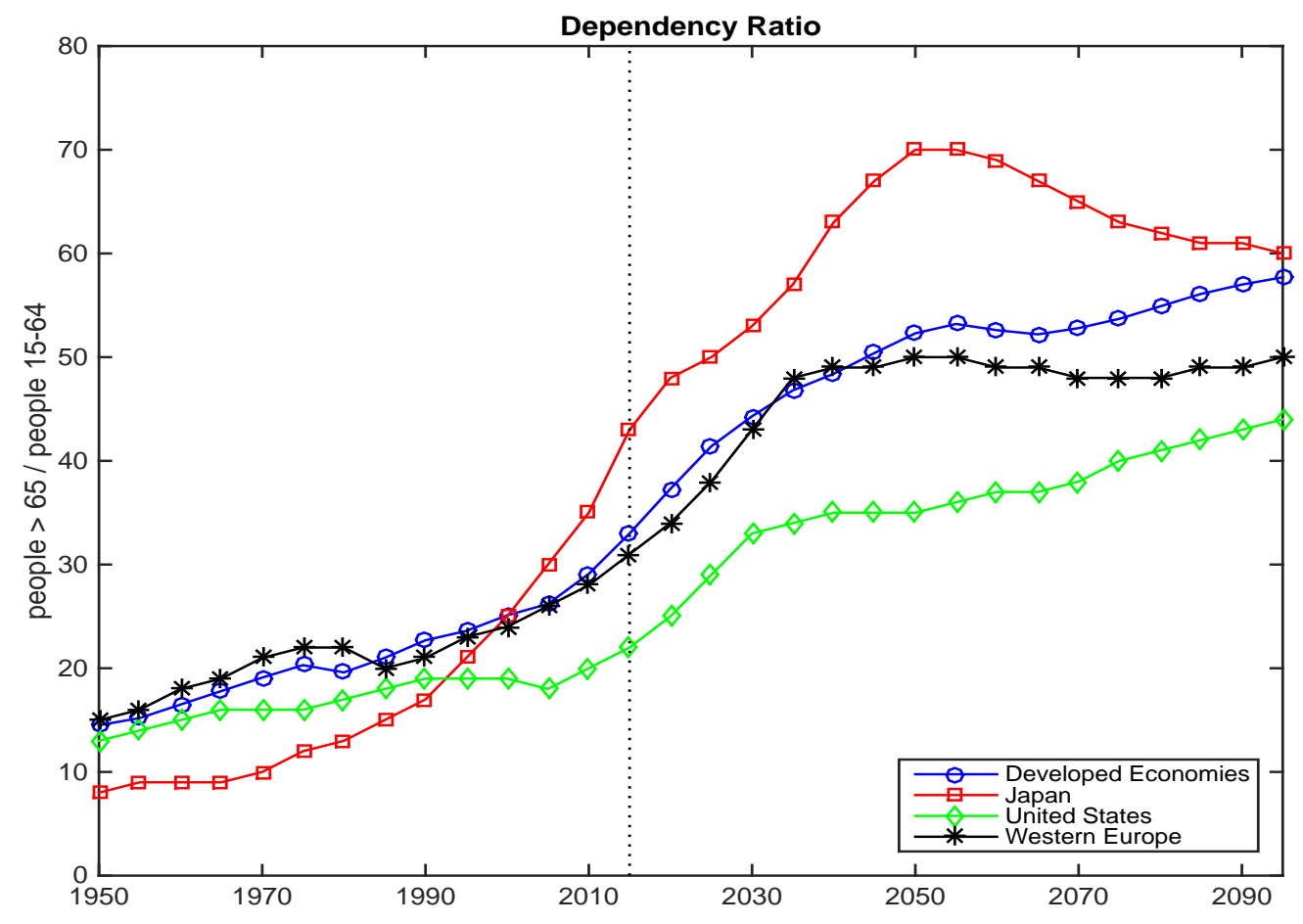

Figure 3: Dependency ratio. Sample: Developed Economies (Northern America, Europe, Japan, Australia, New Zealand; blue line with circles), Japan (red line with squares), United States (green line with diamonds) and Western Europe (black line with stars). Source: United Nations World Population Prospects (2015 Revision).

to save, this change in the composition of the population is akin to a "demand effect" that pushes up aggregate consumption, and puts upward pressure on equilibrium real interest rates. ${ }^{3}$

We allow for demographic developments in the model proposed by Gertler (1999), who studies fiscal policy and social security with stationary population. We calibrate the model to capture salient features of the demographic transition in developed economies, and quantify the effects of the aforementioned channels. ${ }^{4}$ The overall effect of a prototypical demographic transition is to lower the equilibrium interest rate by a significant amount. In particular, for our "representative developed country," the equilibrium annual real rate falls by 1.5 percentage points between 1990 and 2014. The increase in life expectancy accounts for the bulk of the drop in the real interest rate.

We also provide some suggestive anecdotal cross-country evidence that the links between demographics and real interest rates implied by the calibrated model are present in the data. To that

\footnotetext{
${ }^{3}$ Chen et al. (2009) and Ferrero (2010) find small effects of measured changes in population growth rates on the dynamics of U.S. savings and investment in the last three decades, as the demand and supply responses tend to offset each other. See also the survey chapter in Obstfeld and Rogoff (1996) for a review of the macroeconomic consequences of changes in population growth rates in traditional overlapping generation models.

${ }^{4}$ In a world with some capital mobility, real interest rates depend on demographic developments everywhere. In the two-country model with perfect capital mobility of Ferrero (2010), for instance, the global interest rate depends on demographic developments in both the U.S. and the rest of the (developed) world. We simplify along this dimension by focusing on a closed economy and calibrating the model based on averages for developed economies.
} 
end, we compare how the short-term real interest rate varies across pairs of comparable countries, as a function of differences in life expectancy and changes in projected life expectancy (taken one at a time). That is, to provide some evidence on the relationship between real rates and life expectancy, say, we look for pairs of countries with similar changes in projected life expectancy and dependency ratios, but with different actual life expectancies. We then see if the differences in their real rates relate to those differences in life expectancies in a way that is consistent with the implication of the calibrated model.

Through their effect on the real interest rate, demographic trends can thus be one of the key drivers of the so-called "Secular Stagnation" hypothesis (Hansen, 1939). In resuscitating this idea, Summers (2014) has emphasized exactly how in such an environment the equilibrium real interest rate would be low, and potentially negative. ${ }^{5}$

Low and declining real interest rates carry important challenges for the conduct of monetary policy, especially in light of the zero lower bound on monetary policy. We briefly revisit this issue in the context of our framework. In addition, our paper formalizes and quantifies the effects of other measures that, at least in principle, can undo (or at least mitigate) the effects of the demographic transition on real rates, such as expansionary fiscal policies and structural reforms.

The rest of the paper proceeds as follows. Section 2 presents the model, with particular focus on the life-cycle dimension. Section 3 presents our quantitative experiments based on the calibrated model. Section 4 provides some anecdotal evidence on the possible links between demographics and real interest rates. Section 5 studies policies that may mitigate or undo the effects of the demographic transition on real interest rates. Finally, Section 6 concludes.

\section{The Model}

As in Gertler (1999), the economy consist of three types of economic agents: households, firms, and the government. Individuals are born workers, and supply inelastically one unit of labor while employed. After retirement, households consume out of their asset income. The two available savings vehicles are physical capital and government bonds. Perfectly competitive firms produce a single good (the numeraire) that is used for both consumption and investment. The government takes spending as given and decides on the mix of lump-sum taxes and one-period debt to satisfy its budget constraint.

We abstract from aggregate uncertainty and consider the effects of unexpected one-time changes in demographic variables in an otherwise perfect-foresight environment. The only source of uncertainty that may potentially affect agents' behavior stems from idiosyncratic retirement and death risk. To keep the model tractable, we make a few assumptions that simplify aggregation without sacrificing the life-cycle dimension.

\footnotetext{
${ }^{5}$ Rachel and Smith (2015) analyze the forces that can account for the decline in real interest rates, and conclude that most of the candidate explanations are likely to be permanent. On the other side of the debate, Hamilton et al. (2015) find little evidence of the permanent nature of the decline in global real interest rates. Their empirical findings emphasize temporary factors, such as deleveraging, shocks to personal discount rates, tightening of financial regulation, trends in inflation, and other cyclical headwinds.
} 


\subsection{Households and Life-Cycle Structure}

At any given point in time, individuals belong to one of two groups: workers $(w)$ or retirees $(r)$. At time $t-1$, workers have mass $N_{t-1}^{w}$ and retirees have mass $N_{t-1}^{r}$. Between periods $t-1$ and $t$, a worker remains in the labor force with probability $\omega_{t}$, and retires otherwise. If retired, an individual survives from period $t-1$ to period $t$ with probability $\gamma_{t}$. ${ }^{6}$ In period $t,\left(1-\omega_{t}+n_{t}\right) N_{t-1}^{w}$ new workers are born. Consequently, the law of motion for the aggregate labor force is

$$
N_{t}^{w}=\left(1-\omega_{t}+n_{t}\right) N_{t-1}^{w}+\omega_{t} N_{t-1}^{w}=\left(1+n_{t}\right) N_{t-1}^{w}
$$

so that $n_{t}$ represents the growth rate of the labor force between periods $t-1$ and $t .{ }^{7}$ The number of retirees evolves over time according to

$$
N_{t}^{r}=\left(1-\omega_{t}\right) N_{t-1}^{w}+\gamma_{t} N_{t-1}^{r}
$$

From (1) and (2), we define the dependency ratio $\left(\psi_{t} \equiv N_{t}^{r} / N_{t}^{w}\right)$, which summarizes the relevant heterogeneity in the population and evolves according to

$$
\left(1+n_{t}\right) \psi_{t}=\left(1-\omega_{t}\right)+\gamma_{t} \psi_{t-1}
$$

Workers inelastically supply one unit of labor, while retirees do not work. ${ }^{8}$ Preferences for an individual of group $z=\{w, r\}$ are a restricted version of the recursive non-expected utility family (Kreps and Porteus, 1978; Epstein and Zin, 1989) that assumes risk neutrality:

$$
V_{t}^{z}=\left\{\left(C_{t}^{z}\right)^{\rho}+\beta_{t+1}^{z}\left[E_{t}\left(V_{t+1} \mid z\right)\right]^{\rho}\right\}^{\frac{1}{\rho}}
$$

where $C_{t}^{z}$ denotes consumption and $V_{t}^{z}$ stands for the value of utility in period $t$. Retirees and workers have different discount factors to account for the probability of death:

$$
\beta_{t+1}^{z}= \begin{cases}\beta \gamma_{t+1} & \text { if } z=r \\ \beta & \text { if } z=w .\end{cases}
$$

The expected continuation value in (3) differs across workers and retirees because of the different

\footnotetext{
${ }^{6}$ Because retirement is an absorbing state in this model, the probability of retiring is perhaps best interpreted as the risk of becoming unable to supply labor.

${ }^{7}$ This specification of population dynamics makes the growth rate of the labor force independent of the retirement probability. In Section 5.3, we entertain an alternative formulation in the context of the discussion of reforms that change the retirement age.

${ }^{8}$ Gertler (1999) shows how to introduce variable labor supply in this framework without sacrificing its analytical tractability. The demographic trends documented in Section 1 would induce individuals to supply more hours and increase participation rates. The data for all advanced economies, instead, display the opposite tendency, that is, a more or less pronounced downward trend for both variables. We thus view the assumption of inelastic labor supply as a natural benchmark for the purposes of our paper. At the same time, government policies around the world are attempting to fight this course, delaying the retirement age. We return to this issue towards the end of the paper.
} 
possibilities to transition between groups:

$$
E_{t}\left\{V_{t+1} \mid z\right\}= \begin{cases}V_{t+1}^{r} & \text { if } z=r \\ \omega_{t+1} V_{t+1}^{w}+\left(1-\omega_{t+1}\right) V_{t+1}^{r} & \text { if } z=w\end{cases}
$$

This life-cycle model is analytically tractable because the transition probabilities $\omega_{t}$ and $\gamma_{t}$ are independent of age and of the time since retirement. ${ }^{9}$ With standard risk-averse preferences, however, this assumption would imply a strong precautionary savings motive for young agents, which is hard to reconcile with actual consumption/savings choices. Risk-neutral preferences with respect to income fluctuations prevent a counterfactual excess of savings by young workers (Farmer, 1990; Gertler, 1999). Nevertheless, the separation of the elasticity of intertemporal substitution $\left(\sigma \equiv(1-\rho)^{-1}\right)$ from risk aversion implied by (3) allows for a reasonable response of consumption and savings to changes in interest rates.

Households consume the final good $C_{t}$ and allocate their wealth among investment in new physical capital $K_{t}$ and bonds issued by the government $B_{t}$. Households rent the capital stock to firms at a real rate $R_{t}^{K}$ and bear the cost of depreciation $\delta \in(0,1)$. Government bonds $B_{t}$ pay a gross return $R_{t}$.

\subsubsection{Retirees}

An individual born in period $j$ and retired in period $\tau$ chooses consumption $C_{t}^{r}(j, \tau)$ and assets $K_{t}^{r}(j, \tau), B_{t}^{r}(j, \tau)$, for $t \geq \tau$ to solve

$$
V_{t}^{r}(j, \tau)=\max \left\{\left(C_{t}^{r}(j, \tau)\right)^{\rho}+\beta \gamma_{t+1}\left[V_{t+1}^{r}(j, \tau)\right]^{\rho}\right\}^{\frac{1}{\rho}},
$$

subject to

$$
C_{t}^{r}(j, \tau)+K_{t}^{r}(j, \tau)+B_{t}^{r}(j, \tau)=\frac{1}{\gamma_{t}}\left\{\left[R_{t}^{K}+(1-\delta)\right] K_{t-1}^{r}(j, \tau)+R_{t-1} B_{t-1}^{r}(j, \tau)\right\}
$$

Additionally, the optimization problem is also subject to the consistency requirement that the retiree's initial asset holdings upon retirement correspond to the assets held in the last period as a worker:

$$
\begin{aligned}
K_{\tau-1}^{r}(j, \tau) & =K_{\tau-1}^{w}(j), \\
B_{\tau-1}^{r}(j, \tau) & =B_{\tau-1}^{w}(j) .
\end{aligned}
$$

At the beginning of each period, retirees turn their wealth over to a perfectly competitive mutual fund industry which invests the proceedings and pays back a premium over the market return equal to $1 / \gamma_{t}$, to compensate for the probability of death (Blanchard, 1985; Yaari, 1965). A retiree who survives between periods $t-1$ and $t$ then makes investment decisions right at the end of period $t-1$.

\footnotetext{
${ }^{9}$ This tractability comes at the cost of not endowing the model with any flexibility to match the empirical age distribution. This additional feature would require an overlapping generation (OLG) model that is more computationally intensive and less analytically tractable. Hence, in our quantitative exercise, we can only target a few demographic statistics. We leave for future research an extensive comparison of the results obtained in this framework with those from a large-scale OLG model, disciplined by a richer set of moments from demographics data.
} 
Appendix ?? derives the Euler equations for government bonds and capital that characterize the problem of a retiree. In the absence of aggregate uncertainty, returns on both assets are equalized:

$$
R_{t}=R_{t+1}^{K}+(1-\delta)
$$

Hence, for convenience, we define total assets for a retiree as

$$
A_{t}^{r}(j, \tau) \equiv K_{t}^{r}(j, \tau)+B_{t}^{r}(j, \tau)
$$

Due to the equality of returns, a retiree's budget constraint (5) can be rewritten compactly as

$$
C_{t}^{r}(j, \tau)+A_{t}^{r}(j, \tau)=\frac{R_{t-1} A_{t-1}^{r}(j, \tau)}{\gamma_{t}}
$$

In Appendix ?? we show that consumption is a fraction of total wealth:

$$
C_{t}^{r}(j, \tau)=\xi_{t}^{r}\left(\frac{R_{t-1} A_{t-1}^{r}(j, \tau)}{\gamma_{t}}\right)
$$

where the marginal propensity to consume satisfies the following first-order non-linear difference equation:

$$
\frac{1}{\xi_{t}^{r}}=1+\gamma_{t+1} \beta^{\sigma}\left(R_{t}\right)^{\sigma-1} \frac{1}{\xi_{t+1}^{r}}
$$

From (8) and (9), asset holdings evolve according to

$$
A_{t}^{r}(j, \tau)=\left(1-\xi_{t}^{r}\right) \frac{R_{t-1} A_{t-1}^{r}(j, \tau)}{\gamma_{t}} .
$$

Finally, the Appendix also shows that the value function for a retiree is linear in consumption:

$$
V_{t}^{r}(j, \tau)=\left(\xi_{t}^{r}\right)^{\frac{\sigma}{1-\sigma}} C_{t}^{r}(j, \tau)
$$

\subsubsection{Workers}

Workers start their life with zero assets. We write the optimization problem for a worker born in period $j$ in terms of total assets $A_{t}^{w}(j) \equiv K_{t}^{w}(j)+B_{t}^{w}(j)$. Specifically, a worker chooses consumption $C_{t}^{w}(j)$ and assets $A_{t}^{w}(j)$ for $t \geq j$ to solve

$$
V_{t}^{w}(j)=\max \left\{\left(C_{t}^{w}(j)\right)^{\rho}+\beta\left[\omega_{t+1} V_{t+1}^{w}(j)+\left(1-\omega_{t+1}\right) V_{t+1}^{r}(j, t+1)\right]^{\rho}\right\}^{\frac{1}{\rho}},
$$

subject to

$$
C_{t}^{w}(j)+A_{t}^{w}(j)=R_{t-1} A_{t-1}^{w}(j)+W_{t}-T_{t}^{w}
$$

and $A_{j}^{w}(j)=0$, where $W_{t}$ represents the real wage and $T_{t}^{w}$ is the total amount of lump-sum taxes paid by each worker. Workers do not turn their wealth over to the mutual fund industry, and hence do 
not receive the additional return that compensates for the probability of death. ${ }^{10}$ The value function $V_{t+1}^{r}(j, t+1)$ is the solution of the problem (4)-(8) above and enters the continuation value of workers, who have to take into account the possibility that retirement occurs between periods $t$ and $t+1$.

In Appendix ?? we present the complete solution to a worker's optimization problem and show that workers' consumption is a fraction of total wealth, defined as the sum of financial and non-financial ("human") wealth

$$
C_{t}^{w}(j)=\xi_{t}^{w}\left(R_{t-1} A_{t-1}^{w}(j)+H_{t}^{w}\right),
$$

where $H_{t}^{w}$ represents the present discounted value of current and future real wages net of taxation, and is independent of individual-specific characteristics:

$$
H_{t}^{w} \equiv W_{t}-T_{t}^{w}+\sum_{v=1}^{\infty} \frac{\left(W_{t+v}-T_{t+v}^{w}\right)}{\prod_{s=1}^{v} \frac{\Omega_{t+s} R_{t+s-1}}{\omega_{t+s}}}=W_{t}-T_{t}^{w}+\frac{\omega_{t+1} H_{t+1}^{w}}{\Omega_{t+1} R_{t}}
$$

As for retirees, workers' marginal propensity to consume $\xi_{t}^{w}$ also evolves according to a first-order non-linear difference equation:

$$
\frac{1}{\xi_{t}^{w}}=1+\beta^{\sigma}\left(\Omega_{t+1} R_{t}\right)^{\sigma-1} \frac{1}{\xi_{t+1}^{w}} .
$$

The adjustment term $\Omega_{t}$ that appears in (12) and (13) depends on the ratio of the marginal propensity to consume of retirees and workers

$$
\Omega_{t} \equiv \omega_{t}+\left(1-\omega_{t}\right)\left(\frac{\xi_{t}^{r}}{\xi_{t}^{w}}\right)^{\frac{1}{1-\sigma}}
$$

In the definition of non-financial wealth (12), the term $\Omega_{t+1} R_{t} / \omega_{t+1}$ constitutes the real effective discount rate for a worker. The first component of the (higher) discounting captures the effect of the finite lifetime horizon (less value attached to the future). The term $\omega_{t+1}$ augments the actual discount factor because workers need to finance consumption during the retirement period (positive probability of retiring).

The dynamics of asset holdings can then be obtained from the budget constraint of a worker and the consumption function (11):

$$
A_{t}^{w}(j)+\frac{\omega_{t+1} H_{t+1}^{w}}{\Omega_{t+1} R_{t}}=\left(1-\xi_{t}^{w}\right)\left(R_{t-1} A_{t-1}^{w}(j)+H_{t}^{w}\right) .
$$

Finally, as for retirees, workers' value function is also linear in their consumption:

$$
V_{t}^{w}(j)=\left(\xi_{t}^{w}\right)^{\frac{\sigma}{1-\sigma}} C_{t}^{w}(j)
$$

\footnotetext{
${ }^{10}$ Allowing workers to access the mutual fund industry would provide complete insurance against the probability of retirement, hence shutting down most of the interesting life-cycle dimensions of the model.
} 


\subsubsection{Aggregation of Households' Decisions}

The marginal propensities to consume of workers and retirees are independent of individual characteristics. Hence, given the linearity of the consumption functions, aggregate consumption of retirees $\left(C_{t}^{r}\right)$ and workers $\left(C_{t}^{w}\right)$ takes the same form of $(9)$ and $(11)$ at the aggregate level: ${ }^{11}$

$$
\begin{aligned}
C_{t}^{w} & =\xi_{t}^{w}\left(R_{t-1} A_{t-1}^{w}+H_{t}\right) \\
C_{t}^{r} & =\xi_{t}^{r} R_{t-1} A_{t-1}^{r}
\end{aligned}
$$

where $A_{t-1}^{z}$ is total financial wealth that members of group $z=\{w, r\}$ carry from period $t-1$ into period $t$, and the aggregate value of human wealth $H_{t}$ evolves according to

$$
H_{t}=W_{t} N_{t}^{w}-T_{t}+\frac{\omega_{t+1} H_{t+1}}{\left(1+n_{t+1}\right) \Omega_{t+1} R_{t}} .
$$

The aggregate consumption function $C_{t}$ is the weighted sum of (14) and (15). If we let $\lambda_{t} \equiv A_{t}^{r} / A_{t}$ denote the share of total financial wealth $A_{t}$ held by retirees, the aggregate consumption function is

$$
C_{t}=\xi_{t}^{w}\left[\left(1-\lambda_{t-1}\right) R_{t-1} A_{t-1}+H_{t}\right]+\xi_{t}^{r}\left(\lambda_{t-1} R_{t-1} A_{t-1}\right)
$$

Relative to the standard neoclassical growth model, the distribution of assets across cohorts is an additional state variable, which keeps track of the heterogeneity in wealth accumulation due to the life-cycle structure. Aggregate assets for retirees depend on the total savings of those who are retired in period $t$ as well as on the total savings of the fraction of workers who retire between periods $t$ and $t+1:$

$$
A_{t}^{r}=R_{t-1} A_{t-1}^{r}-C_{t}^{r}+\left(1-\omega_{t+1}\right)\left(R_{t-1} A_{t-1}^{w}+W_{t} N_{t}^{w}-T_{t}-C_{t}^{w}\right) .
$$

Aggregate assets for workers depend only on the savings of the fraction of workers who remain in the labor force:

$$
A_{t}^{w}=\omega_{t+1}\left(R_{t-1} A_{t-1}^{w}+W_{t} N_{t}^{w}-T_{t}-C_{t}^{w}\right) .
$$

The law of motion for the distribution of financial wealth across groups obtains from substituting expressions (14) and (17) into (16):

$$
\lambda_{t} A_{t}=\left(1-\omega_{t+1}\right) A_{t}+\omega_{t+1}\left(1-\xi_{t}^{r}\right) \lambda_{t-1} R_{t-1} A_{t-1}
$$

Expression (18) relates the evolution of the distribution of wealth $\lambda_{t}$ to the aggregate asset position $A_{t}$. From expression (7) and its counterpart for workers, total assets equal the sum of the aggregate capital stock and government bonds:

$$
A_{t}=K_{t}+B_{t}
$$

\footnotetext{
${ }^{11}$ An aggregate variable $S_{t}^{z}$ for group $z=\{w, r\}$ takes the form $S_{t}^{z} \equiv \int_{0}^{N_{t}^{z}} S_{t}^{z}(i) d i$.
} 


\section{$2.2 \quad$ Firms and Production}

The supply side of the model is completely standard. Competitive firms employ labor hired from households and capital rented from both workers and retirees to produce a homogeneous final good, which is used for both consumption and investment purposes. The production function is CobbDouglas with labor-augmenting technology.

The problem of a representative firm can be written as

$$
\begin{aligned}
\max _{N_{t}^{w}, K_{t-1}} & Y_{t}-\left(W_{t} N_{t}^{w}+R_{t}^{K} K_{t-1}\right), \\
\text { s.t. } & Y_{t}=\left(X_{t} N_{t}^{w}\right)^{\alpha} K_{t-1}^{1-\alpha},
\end{aligned}
$$

where $\alpha \in(0,1)$ is the labor share and the technology factor $X_{t}$ grows exogenously at rate $x_{t}$ :

$$
X_{t}=\left(1+x_{t}\right) X_{t-1}
$$

The first-order conditions for labor and capital are

$$
\begin{aligned}
W_{t} N_{t}^{w} & =\alpha Y_{t}, \\
R_{t}^{K} K_{t-1} & =(1-\alpha) Y_{t} .
\end{aligned}
$$

\subsection{Fiscal Policy}

The government issues one-period debt $B_{t}$ and levies lump-sum taxes to finance a given stream of spending $G_{t}$. The flow government budget constraint is

$$
B_{t}=R_{t-1} B_{t-1}+G_{t}-T_{t}
$$

For simplicity, and to focus solely on the role of demographics to explain the decline in the real interest rate, we assume that the ratio between government spending and GDP is constant $\left(G_{t}=g Y_{t}\right)$. We also impose a fiscal rule that requires the government to keep a constant debt-to-GDP ratio:

$$
B_{t}=b Y_{t}
$$

which implies a zero total deficit in percentage of GDP in each period. We come back to fiscal policy considerations at the end of the paper.

\subsection{Equilibrium}

Given the dynamics for the demographic processes $n_{t}, \omega_{t}$, and $\gamma_{t}$, and the growth rate of productivity $x_{t}$, a competitive equilibrium for this economy is a sequence of quantities $\left\{C_{t}^{r}, C_{t}^{w}, C_{t}, A_{t}^{r}, A_{t}^{w}, A_{t}\right.$, $\left.\lambda_{t}, H_{t}, Y_{t}, K_{t}, I_{t}, V_{t}^{r}, V_{t}^{w}, B_{t}, T_{t}\right\}$, marginal propensities to consume $\left\{\xi_{t}^{r}, \xi_{t}^{w}, \epsilon_{t}, \Omega_{t}\right\}$, prices $\left\{R_{t}, R_{t}^{K}\right.$, $\left.W_{t}\right\}$, and dependency ratio $\psi_{t}$ such that: 
1. Retirees and workers maximize utility subject to their budget constraints, taking market prices as given, as outlined in sections 2.1.1 and 2.1.2.

2. Firms maximize profits subject to their technology (section 2.2).

3. The fiscal authority chooses the mix of debt and taxes to satisfy its budget constraint (section $2.3)$.

4. The markets for labor, capital and goods clear. In particular, the economy-wide resource constraint is

$$
Y_{t}=C_{t}+I_{t}+G_{t}
$$

where investment $I_{t}$ satisfies the law of motion of capital:

$$
K_{t}=(1-\delta) K_{t-1}+I_{t}
$$

We focus on an equilibrium with constant productivity growth (i.e. $x_{t}=x, \forall t$ ) and constant probability of retirement, $\left(\omega_{t}=\omega, \forall t\right) .{ }^{12}$ We solve for the steady state and characterize the dynamics of variables expressed in efficiency units (i.e., $s_{t} \equiv S_{t} /\left(X_{t} N_{t}^{w}\right)$ for any variable $\left.S_{t}\right)$. The next section explains the experiments in details.

\section{Demographics and Real Rates}

This section analyzes the link between demographics and real interest rates. First, we discuss the calibration of the model and the results of the two main experiments, which consist of a decline in population growth and an increase in the survival probability. We then revisit the same experiments in a version of the model in which retirees receive social security benefits from the government.

\subsection{Calibration and Experiment}

Each period corresponds to one year. Individuals are born at age 20. We calibrate the probability of remaining in the labor force $\omega$ to 0.9778 , which implies an average retirement age of 65 . This value is consistent with the current retirement age in the majority of OECD countries. To calibrate the initial growth rate of the labor force and probability of surviving, we use data from the United Nation World Population Prospects (the 2015 revision). The initial value of labor force growth $\left(n_{1990}=0.55 \%\right)$ matches directly the average population growth rate for developed economies in 1990, and is only slightly lower than the growth rate in $1970(0.77 \%)$. The initial surviving probability $\gamma_{1990}$ is calibrated to match the average dependency ratio among developed economies in 1990 (equal to 21\%), conditional on the values of $n$ and $\omega$, using the steady-state model counterpart

$$
\psi=\frac{1-\omega}{1+n-\gamma} .
$$

\footnotetext{
${ }^{12}$ Section 5.3 relaxes this assumption to consider how changes in retirement age affect the dynamics of the real interest rate.
} 
Table 1: Parameter values and steady state exogenous variables.

\begin{tabular}{llrl}
\hline \hline$\alpha$ & $=$ & 0.67 & Labor share \\
$\delta$ & $=$ & 0.10 & Depreciation rate \\
$\sigma$ & $=$ & 0.50 & Elasticity of intertemporal substitution \\
$x$ & $=$ & 0.01 & Productivity growth rate \\
$g$ & $=$ & 0.20 & Government spending (\% of GDP) \\
$b$ & $=$ & 0.60 & Government debt (\% of GDP) \\
$\beta$ & $=0.9631$ & Individual discount factor \\
$\omega$ & $=$ & 0.9778 & Probability of remaining in the labor force \\
$n_{1990}=$ & 0.0055 & Initial growth rate of the labor force \\
$\gamma_{1990}=$ & 0.8998 & Initial probability of surviving \\
$n_{2100}=$ & 0.0001 & Final growth rate of the labor force \\
$\gamma_{2100}$ & $=0.9616$ & Final probability of surviving \\
\hline \hline
\end{tabular}

The implied value (equal to 0.8998) yields an average retirement period of 10 years, with overall life expectancy of 75 years. ${ }^{13}$ We follow a similar approach to pin down the final values of $n$ and $\gamma$, respectively equal to 0.0001 and 0.9616 . Population growth rate in 2100 is projected to be barely positive and the dependency ratio is expected to reach almost $58 \%$, which returns a value of $\gamma$ equal to 0.9616 in the final steady state. The average retirement period therefore increases to 26 years, and overall life expectancy rises to 91 years. ${ }^{14}$

This "representative" transition for developed economies masks some heterogeneity among countries. For example, Japan is at one extreme of the range, with population growth rates currently in negative territory, and life expectancy well above 80 years. At the opposite end of the spectrum, the United States has a population growth rate just below $1 \%$ and life expectancy well below 80 years. This range is projected to remain roughly stable throughout the current century.

The other parameters of the model are fairly standard in the literature. The elasticity of intertemporal substitution $\sigma$ is set to 0.5, consistent with the estimates in Hall (1988) and Yogo (2004). The labor share of output $\alpha$ equals 0.667 and the depreciation rate $\delta$ is set to 0.1 , in line with the average post-war values for several advanced economies. Total factor productivity grows at $1 \%$ per year, higher than for the average TFP growth rate for G7 economies post-1990 (0.3\%) but close to the value in a broader sample of OECD countries. Government spending represents $20 \%$ of GDP while government debt corresponds to $60 \%$ of GDP. These values are close to their data counterparts for G7 countries post-1990 (19.2\% and 52.3\% respectively). Finally, the individual discount factor $\beta$ is chosen so that the real interest rate in the initial steady state equals $4 \%$, close to the average ex-post real interest rate on short-term government bonds in 1990 for the sample of countries in Figure 1.

The main experiment consists of computing the transition from the initial steady state in 1990 to a final steady state in $2100 .{ }^{15}$ Demographic variables are the only exogenous drivers of the simulation.

\footnotetext{
${ }^{13}$ Although our calibration for the probability of surviving targets the dependency ratio, this initial life expectancy is in line with data for life expectancy at birth among developed economies in 1990.

${ }^{14}$ In our model, the increase in life expectancy affects all individuals independently of their age. In the data, the increase in life expectancy at 65 between 1990 and 2015 for OECD countries is only one year less than the increase in life expectancy at birth.

${ }^{15}$ Figure 2 shows that population growth rates have been falling at since the 1970s, and life expectancy has progressively increased since the end of World War II. The choice of 1990 as the starting year for our experiment is, therefore, quite
} 

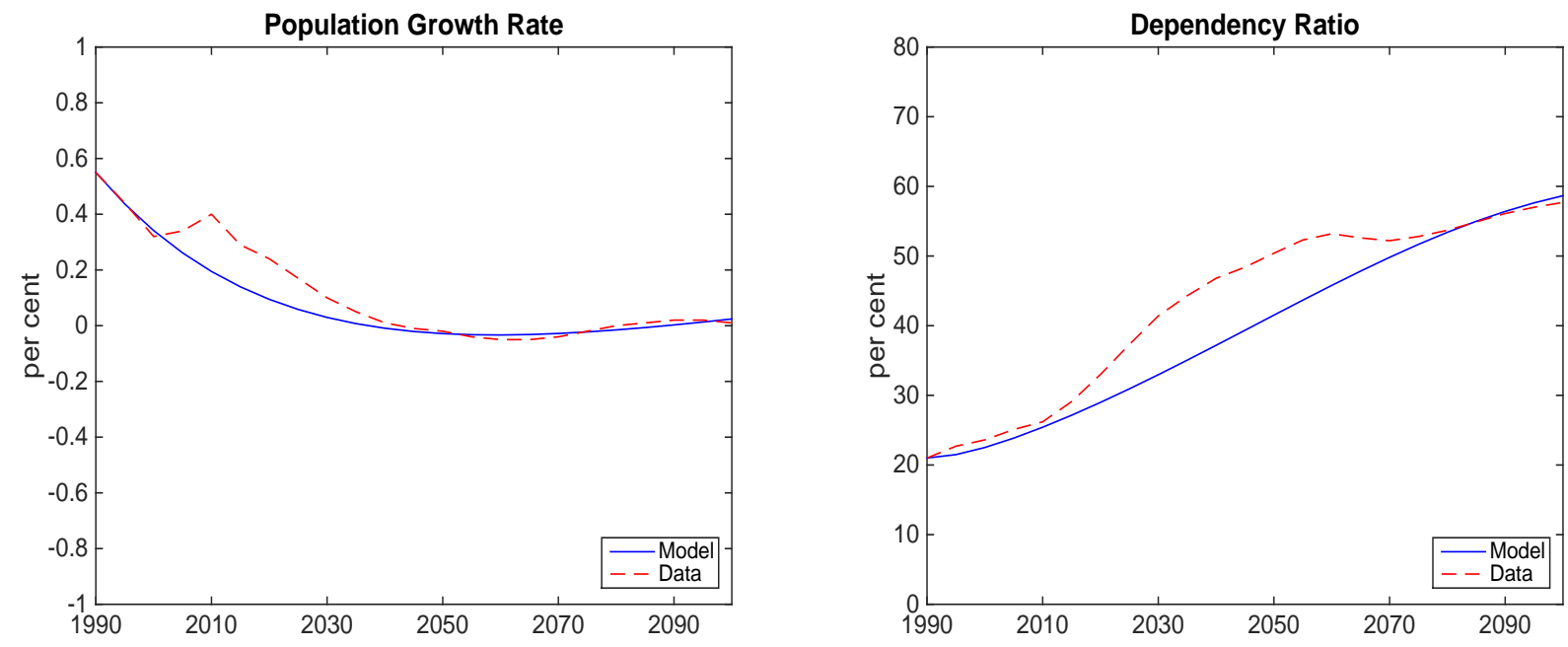

Figure 4: Left panel: Population growth rate in the model (continuous blue line) and in the data (dashed red line). Right panel: Dependency ratio in the model (continuous blue line) and in the data (dashed red line).

We assume that $n_{t}$ and $\gamma_{t}$ follow

$$
\begin{aligned}
& n_{t}=n_{1990} \exp \left(u_{n t}-v_{n t}\right), \\
& \gamma_{t}=\gamma_{1990} \exp \left(u_{\gamma t}-v_{\gamma t}\right),
\end{aligned}
$$

where $u_{i t}$ and $v_{i t}$ (for $i=\{n, \gamma\}$ ) are stationary $\operatorname{AR}(1)$ processes with common innovation $\varepsilon_{i t}$. We choose the persistence parameters of the autoregressive processes and the initial innovations (the only unanticipated shock) such that the implied process for population growth and the dependency ratio roughly match the data. ${ }^{16}$

Figure 4 compares the evolution of the exogenous demographic variables in the model with their empirical counterparts. The left panel shows that, except for a short-lived bump, the assumed process fits the evolution (and forecasts) of population growth in the data very closely. The right-hand side panel shows that the dependency ratio in the model is smoother than in the data. The calibrated path remains very close to the data for the first thirty years and the last twenty years of the sample, but misses a non-negligible part of the projected increase in the dependency ratio in the next 25 years. As a result, the implied probability of surviving that we back out of the dependency ratio in the

arbitrary. For example, we could have alternatively initialized the model out of steady state to analyze the transition. From a practical perspective, starting the model in a steady state avoids the complication of finding the right set of initial conditions each time we run a different experiment, without high costs in terms of computational precision, at least in a perfect foresight environment. More substantially, we want to focus on a period in which confounding factors (such as changes in trend productivity) do not influence too much the dynamics of real interest rates, at least at low frequencies. Therefore, we decided to focus on the recent period, in which the drop in real interest rates is quite visible, and study to which extent demographic developments can explain this decline within our calibrated model.

${ }^{16}$ With stationary driving processes, the model eventually reverts to the initial steady state. But the reversion is very slow, as the two autoregressive components have similar persistence, so that the demographic processes mimic non-stationary time series. The results for the 1990-2014 window are essentially insensitive to the path of reversal after 2100 . 


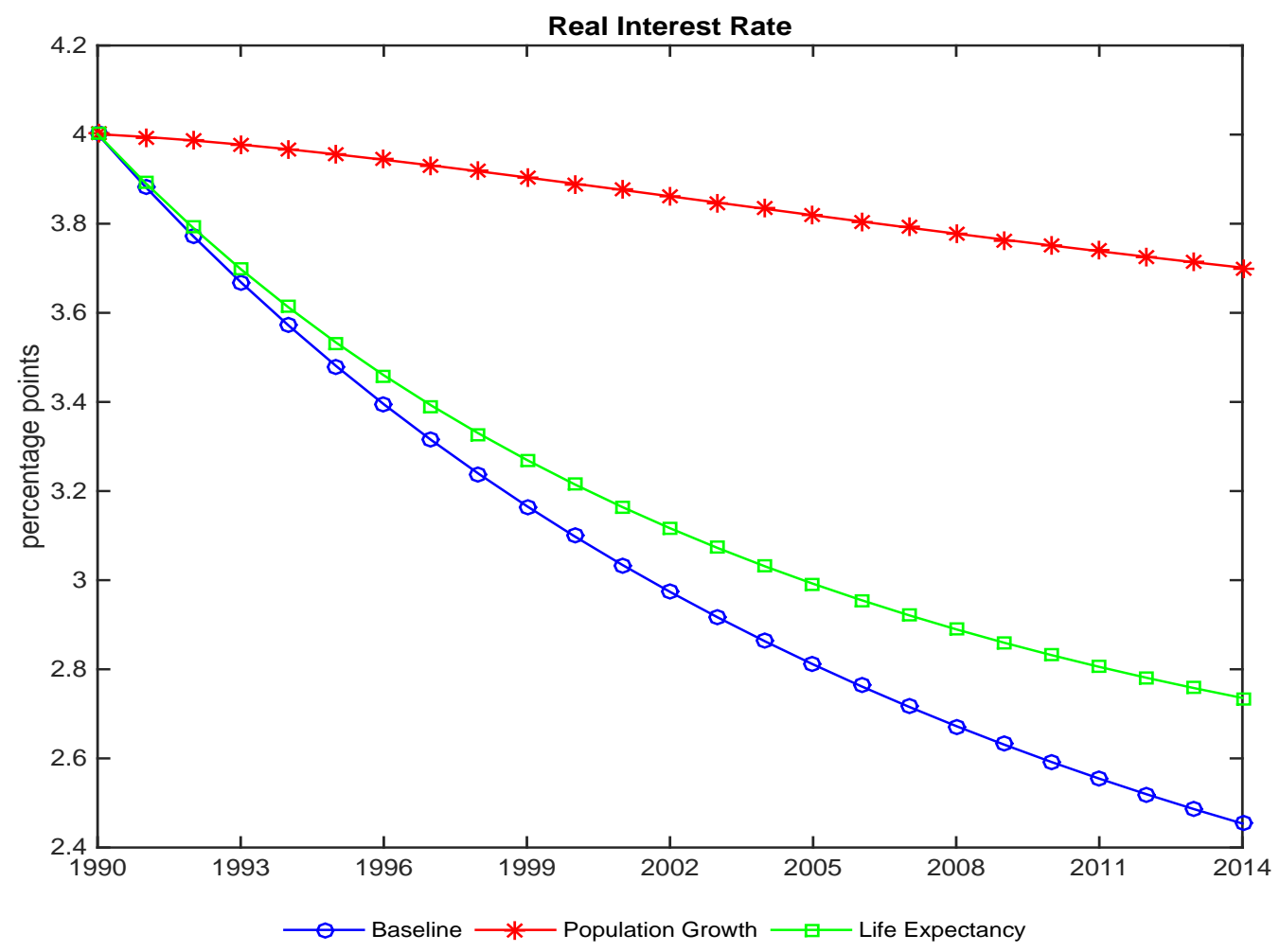

Figure 5: Simulated real interest rate following (i) the full demographic transition (blue line with circles), (ii) only the decrease in the population growth rate (red line with stars), (iii) only the increase in the probability of surviving (green line with squares).

model corresponds to a slower aging profile than the United Nations projections currently imply. We shall see in the next section that underestimating the increase of the dependency ratio (and hence of the increase in life expectancy) represents a conservative approach in terms of the effects of the demographic transition on the real interest rate. In this sense, our results may actually constitute a lower bound for the fall of the real interest rate attributable to demographic forces.

\subsection{Effects of the Demographic Transition on the Real Interest Rate}

Figure 5 shows the main result of the paper. In response to the demographic transition, the real interest rate progressively falls from 4\% in 1990 to approximately $2.5 \%$ in 2014 (blue line with circles). The model therefore explains about one third of the overall decline observed in the data. Furthermore, the simulation predicts the real interest rate will fall an additional 50 basis points over the next forty years, before stabilizing around its new steady state value of $2 \%$.

The figure also reports the model real interest rate in two counterfactual simulations. The first (the red line with stars) is the real interest rate implied by the decline in population growth only, holding the probability of surviving at its initial steady state value. Conversely, the second counterfactual (the green line with squares) is the real interest rate when only the probability of surviving increases as in the baseline case, holding the population growth rate at its initial steady state value. 
This decomposition represents the second important result in our paper. The increase in the probability of surviving, rather than the fall in the population growth rate, is mainly responsible for the decline in the real interest rate explained by the demographic transition.

The higher probability of surviving acts like a preference "shock" that induces retirees to save more, since this group effectively discounts the future at rate $\beta \gamma_{t+1}$ (see expression 4). But at each point in time, workers attach some probability to retirement (expression 10). Therefore, the increase in life expectancy also affects this group through their continuation value. As a result, both groups increase their savings, thus putting downward pressure on the real interest rate.

This effect can be seen analytically by differentiating the marginal propensity to consume of each group at steady state. Starting with retirees, the partial derivative of their marginal propensity to consume is

$$
\frac{\partial \xi^{r}}{\partial \gamma}=-\beta^{\sigma} R^{\sigma-1}\left[1+(\sigma-1) \varepsilon_{R, \gamma}\right]<0,
$$

where $\varepsilon_{R, \gamma} \equiv(\partial R / R) /(\partial \gamma / \gamma)<0$ is the elasticity of the real interest rate with respect to the probability of surviving. The first term captures the direct effect discussed above. The second one is a general equilibrium effect, as the marginal propensity to consume itself depends on the real interest rate. In this respect, the assumption that the elasticity of intertemporal substitution is smaller than one is important. With the logarithmic version of Epstein-Zin preferences (which corresponds to the case $\sigma=1$ ), only the direct effect survives. And if the elasticity of intertemporal substitution were assumed to be larger than one, the general equilibrium effect would partially offset the direct one.

Using the implicit function theorem, we can also derive the effect of a change in life expectancy on the marginal propensity to consume of workers:

$$
\frac{\partial \xi^{w}}{\partial \gamma}=-\frac{\beta^{\sigma}(\Omega R)^{\sigma-1}\left[(\sigma-1) \varepsilon_{R, \gamma}-\left(\frac{\Omega-\omega}{\Omega}\right) \varepsilon_{\xi^{r}, \gamma}\right]}{\gamma\left[1+\beta^{\sigma}(\Omega R)^{\sigma-1}\left(\frac{\Omega-\omega}{\Omega}\right) \frac{1}{\xi^{w}}\right]}<0,
$$

where $\Omega-\omega=(1-\omega) \xi^{r} / \xi^{w}>0$ and $\varepsilon_{\xi^{r}, \gamma} \equiv\left(\partial \xi^{r} / \xi^{r}\right) /(\partial \gamma / \gamma)<0$ because of equation (19) above. The assumption that the elasticity of intertemporal substitution is smaller than one, while not crucial, strengthens the result also in this case.

The two top panels of Figure 6 show the quantitative importance of an increase in the probability of surviving on the marginal propensity to consume of workers and retirees, respectively. The marginal propensity to consume of retirees remains higher than the workers' one, but it falls by more (about one fourth against one sixth). Retirees, however, hold more assets, therefore their consumption falls less (middle panels). In fact, the larger decline in the marginal propensity to consume of retirees implies that their asset accumulation is proportionally larger than for workers, so that the distribution of wealth shifts in favor of the former group (bottom-left panel). In the aggregate, consumption falls by about half a percentage point (bottom-right panel). Therefore, the demographic transition-and in particular the higher probability of surviving- does not carry large consequences for macroeconomic aggregates. Rather, it is the real interest rate that bears the bulk of the adjustment.

The other notable aspect of the demographic transition is the fall in the population growth rate. As mentioned, the repercussions for the real interest rate are quantitatively less significant than those 

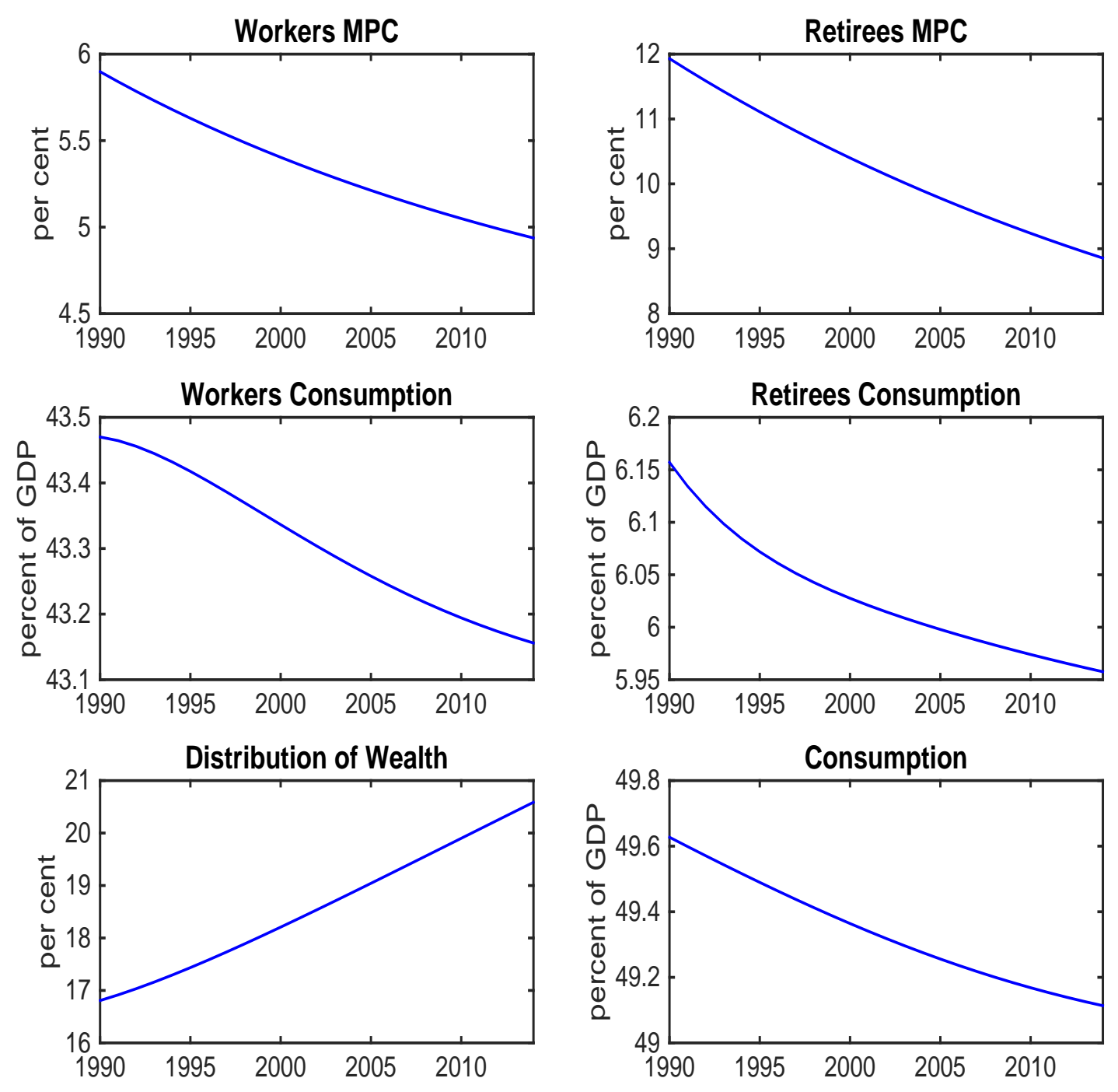

Figure 6: Simulated marginal propensity to consume for workers (top left) and retirees (top right), consumption for workers (middle left) and retirees (middle right), distribution of wealth (bottom left), and aggregate consumption (bottom right), in response to the increase in the probability of surviving.

of the increase in life expectancy. The intuition is that a falling population growth rate brings about two effects working in opposite directions. On the one hand, a lower population growth rate reduces the pool of workers, thus increasing the capital-labor ratio. Therefore, the rental rate decreases, and, by no arbitrage, so does the real rate. On the other hand, however, a lower population growth rate progressively increases the dependency ratio - the ratio of retirees to workers. Because retirees have a larger marginal propensity to consume, this effect tends to offset the consequence of the less efficient use of capital. Overall, the effect is negative, but quantitatively small. This finding is therefore consistent with the view that the negative effects of the demographic transition on the real interest 
rate may be small and temporary (see, for example, Erfurth and Goodhart, 2014). However, this conclusion neglects the key role of the increase in life expectancy that our paper highlights. ${ }^{17}$

\subsection{Social Security}

So far we have assumed that individuals self-finance their consumption after retirement through savings during their employment spell. While this approach may be a good approximation for some countries (e.g. the United States), in several others (especially in continental Europe) public pension systems provide the bulk of the pension funds. In this section, we consider a simple modification of the model that allows us to study whether this more realistic arrangement changes our results.

The key amendment to our baseline model is the introduction of a lump-sum transfer $E_{t}^{r}$ to each retiree. The budget constraint of an individual born in period $j$ and retired in period $\tau$ becomes

$$
C_{t}^{r}(j, \tau)+A_{t}^{r}(j, \tau)=\frac{R_{t-1} A_{t-1}^{r}(j, \tau)}{\gamma_{t}}+E_{t}^{r}
$$

Appendix ?? shows that the consumption function that solves a generic retiree's optimization problem is

$$
C_{t}^{r}(j, \tau)=\xi_{t}^{r}\left[\frac{R_{t-1} A_{t-1}^{r}(j, \tau)}{\gamma_{t}}+S_{t}^{r}\right],
$$

where $S_{t}^{r}$ represents the present discounted value of social security benefits for a retiree:

$$
S_{t}^{r}=E_{t}^{r}+\frac{S_{t+1}^{r}}{R_{t} / \gamma_{t+1}}
$$

While the budget constraint for a worker does not change, the presence of social security transfers alters the consumption function because workers anticipate the extension of benefits after retirement:

$$
C_{t}^{w}(j)=\xi_{t}^{w}\left[R_{t-1} A_{t-1}^{w}(j)+H_{t}^{w}+S_{t}^{w}\right]
$$

where $S_{t}^{w}$ is the present discounted value of social security benefits for a worker after retirement:

$$
S_{t}^{w}=\frac{\left(\Omega_{t+1}-\omega_{t+1}\right) S_{t+1}^{r}+\omega_{t+1} S_{t+1}^{w}}{\Omega_{t+1} R_{t}}
$$

Importantly, the presence of social security benefits leaves unchanged the expressions for the marginal propensities to consume of both retirees and workers. Thus, aggregation remains feasible and follows the same steps as in the baseline model.

The only other relevant change in the model is that the government now needs to also fund social security as an additional expenditure item:

$$
B_{t}=R_{t-1} B_{t-1}+G_{t}+E_{t}-T_{t}
$$

\footnotetext{
${ }^{17}$ Our paper focuses on the savings margin. Recent results on the detrimental effects of lower population growth on labor supply and participation rates (Fujita and Fujiwara, 2014), and on innovation (Aksoy et al., 2015) are thus complementary to our work. Eggertsson and Mehrotra (2014) show how a decline in population growth rate can be equivalent to a tightening of borrowing constraints, and thus reduce the equilibrium real interest rate.
} 


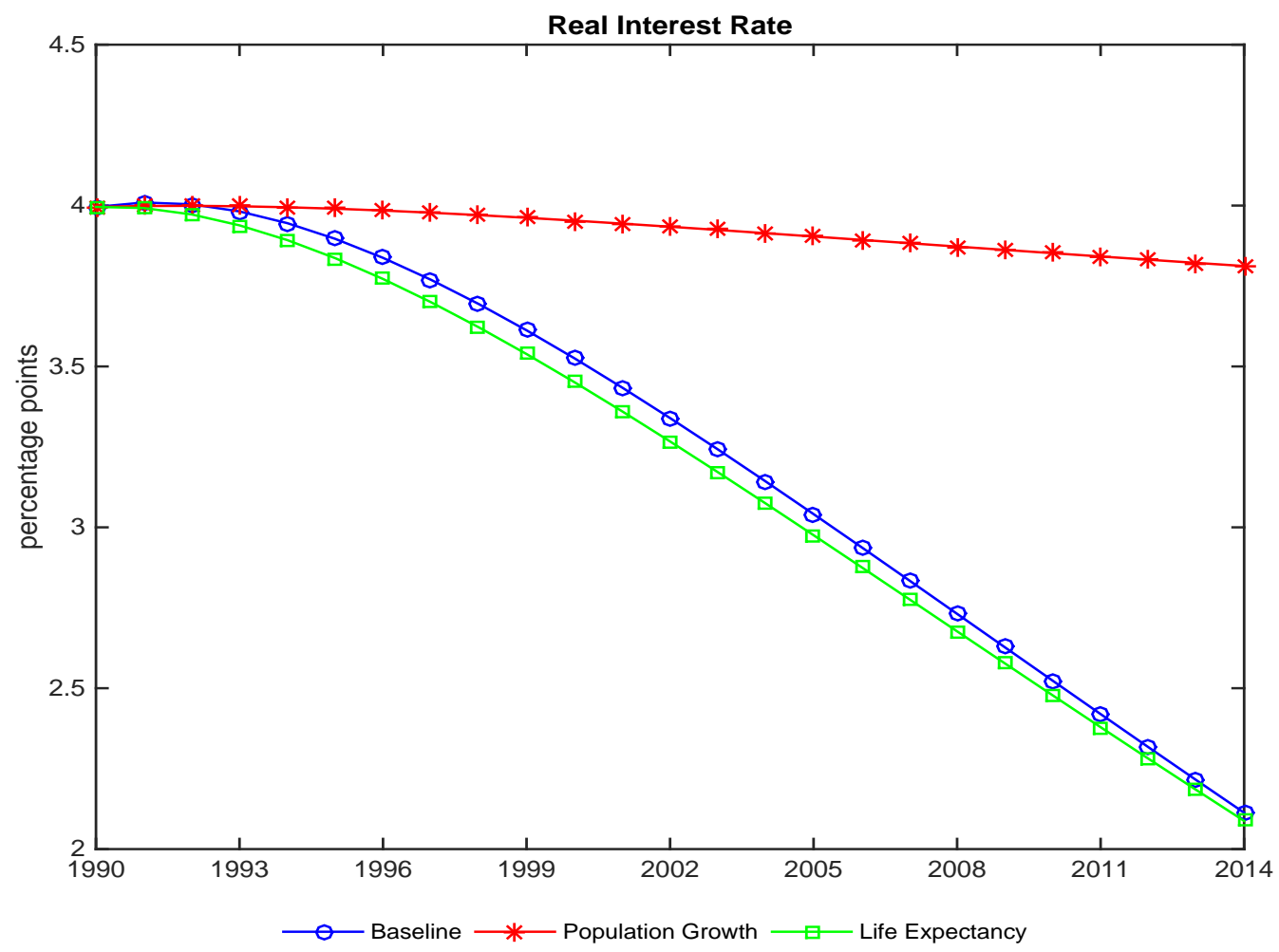

Figure 7: Simulated real interest rate in the model with social security following (i) the full demographic transition (blue line with circles), (ii) only the decrease in the population growth rate (red line with stars), (iii) only the increase in the probability of surviving (green line with squares).

The key parameter to calibrate in this version of the model is the total amount of transfers to retirees. An individual retiree receives a constant fraction $r r$ (the replacement rate) of the wage net of taxes $E^{r}=\operatorname{rr}\left(W-T^{w}\right)$. We calibrate the ratio between transfers and GDP aggregating the previous expression to obtain

$$
\frac{E}{Y}=\operatorname{rr} \psi\left(\frac{W N^{w}-T}{Y}\right)
$$

To calibrate $r r$, we look at the average net replacement rate for OECD countries, which is currently about 60\%, having increased between 2005 and 2011 and decreased ever since. For $\psi$, we use the average dependency ratio between 1990 and 2015 for developed economies (24.6\%). Karabarbounis and Neiman (2014) document the global decline of the labor share since 1980. The median labor share among OECD countries since 1990 is slightly below 50\%, while the GDP-weighted average among G7 countries is almost $54 \%$. We use the mid-point of this range for our calibration of $W N^{w} / Y$. Finally, we fix the tax burdens on labor income $T / Y$ to $30 \%$, consistent with the average for OECD countries between 2000 and 2014. This approach delivers a ratio of transfers to GDP of $3.25 \%$. The rest of the calibration corresponds to the baseline experiment, except that we adjust the individual discount factor so that the real interest rate in the initial steady state remains $4 \%$.

Figure 7 repeats the decomposition of the real interest rate that we performed in Section 3.2. The 
presence of social security strengthens the message of the demographics experiment compared to the baseline case. Over the period 1990-2014, the real interest rate falls by almost two percentage points, and the increase in life expectancy now accounts for even more of the decline. Two differences are also evident. First, the real interest rate remains roughly flat during the first couple of years of the simulation, but then the drop is faster than in the baseline case. Going forward, the real interest rate stabilizes around $-1 \%$ towards the end of the simulation horizon (a Secular Stagnation steady state!) Second, in this case, life expectancy alone would imply an even larger (although quantitatively small) fall of the real interest rate.

In principle, we may have expected that if the government provides transfers after retirement, individuals would have lesser incentives to save during employment, and thus this effect would mute the consequences of the demographic transition on the real interest rate. This channel is at work during the early stages of the simulation, but its quantitative relevance is not particularly significant. Instead, as the demographic transition continues, maintaining a constant level of transfers to a larger pool of retirees requires that output keeps pace. The only way the economy can achieve this higher growth rate is through savings and investment. Therefore, the real interest rate must fall. And a higher population growth - as in the counterfactual with population growth kept at the initial steady state - implies an even higher savings rate, because future transfers will be even higher, in spite of the positive contribution to output that a larger number of workers provides.

These results capture some of the low frequency forces currently at play in many advanced economies, especially in continental Europe but also elsewhere around the world. Public pension systems currently in place are becoming less and less sustainable. All reforms, either recently implemented or under consideration, entail a reduced generosity of government-provided pensions, together with a switch towards private plans for the younger generations. These considerations may partially temper the quantitative relevance of the simulations in this section, although the consequences for the real interest rate are unlikely to be substantially different.

\section{Anecdotal Evidence}

The model just presented suggests different possible links between demographics and real interest rates. Here we resort to country-pair comparisons to provide some anecdotal evidence of these relationships in the data. The key result from the model is that the demographic transition - and, in particular, the increase in life expectancy — drives the decline in real interest rate observed during the last two and half decades. Therefore, in the data, we compare how the short-term real interest rate varies for pairs of countries that differ only in terms of life expectancy, either actual or projected. We want to stress that this exercise is purely illustrative, and by no means aims to provide definitive empirical evidence on these patterns.

To perform our analysis, we consider data for two base years, 1990 and 2005. In particular, we calculate five-year averages, centered at 1990 and 2005, of the short-term real interest rate and life expectancy. ${ }^{18}$ To calculate the projected change in life expectancy, we consider the United Nations

\footnotetext{
${ }^{18}$ This choice of dates, therefore, excludes the GFC, when monetary authorities across the globe aggressively reduced policy rates, in many cases all the way to the zero lower bound.
} 


\section{Short yields and life expectancy}

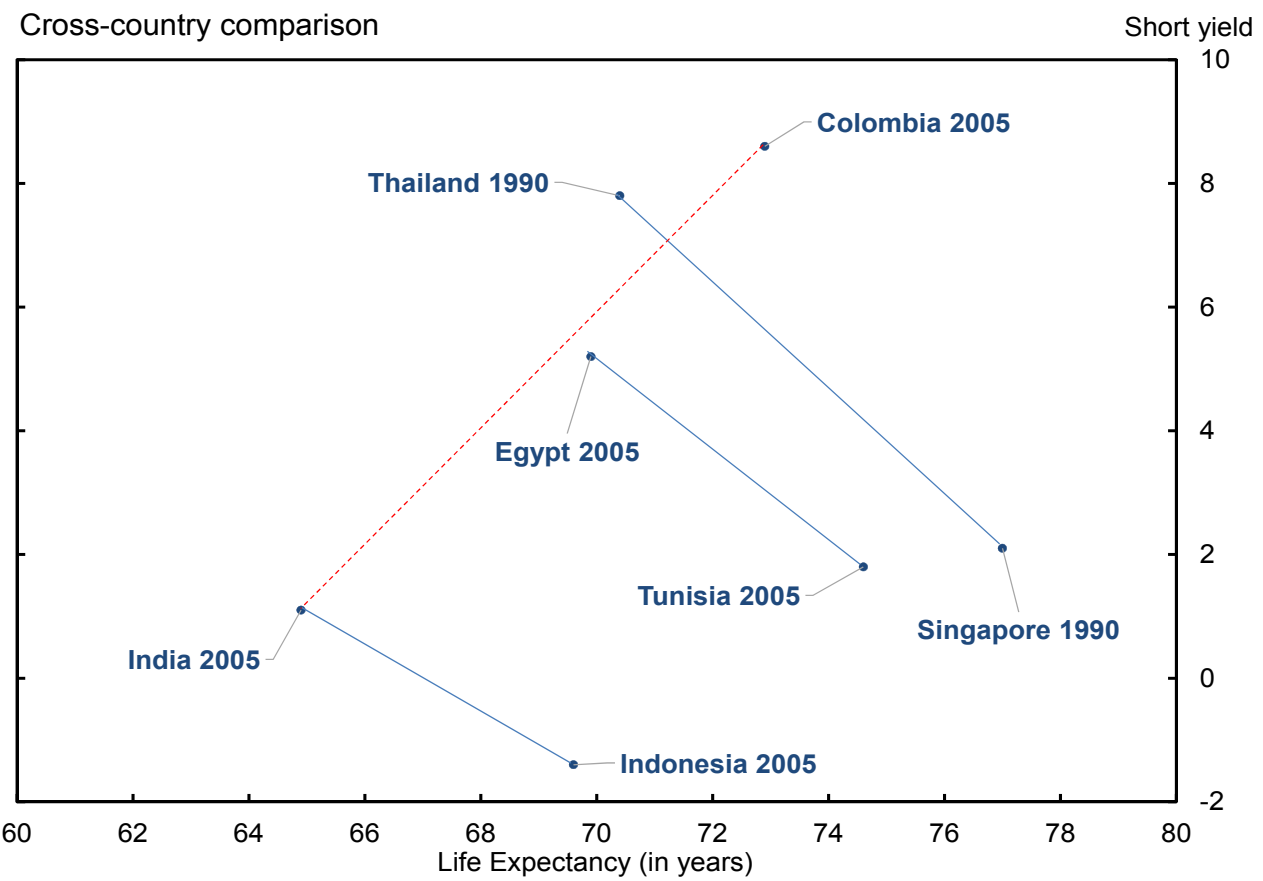

Figure 8: Country-pairs comparison of short-term real rates and life expectancy.

forecast for life expectancy in two 15-year windows, between 1990 and 2005 (as of 1990), and 2005 and 2020 (as of 2005). ${ }^{19}$

Figure 8 reports the first set of country-pairs. The figure shows short-term real rates and life expectancy for pairs of countries with similar projected change in life expectancy and dependency ratios at the indicated base-year. For example, in 1990, Thailand and Singapore had similar projected change in life expectancy (and similar dependency ratios), but differed in their short-term rates and life expectancy. Singapore had higher life expectancy and lower short-term yields. Similar patterns hold for other country-pairs, such as Egypt-Tunisia in 2005, and India-Indonesia in the same year. All three pairs of countries featured similar projected changes in life expectancy (and dependency ratios), and the country with higher life expectancy also had lower short-term real interest rates. Obviously, we can easily find exceptions. For example, the comparison between India and Colombia in 2005 deviates from the pattern highlighted above. In 2005, Colombia and India had similar projected changes in life expectancy, but Colombia had higher life expectancy and higher short-term real rates than India.

Figure 9 examines the relationship between short-term real yields and projected changes in life expectancy for pairs of countries with similar life expectancy. The figure shows that, for example around 1990, South Korea had a larger projected increase in life expectancy and a lower short-term real yields than Chile. Again, exceptions are not hard to find. South Korea's yield, for example, was higher than Mexico's, despite also having a larger projected increase in life expectancy.

The patterns reported in Figures 8 and 9 hint that the connections between demographics and real

\footnotetext{
${ }^{19}$ For all country-pairs reported in this exercise, the two countries in each comparison have similar old dependency ratios, calculated as five-year averages centered at 1990 and 2005.
} 


\section{Short yields and projected change in life expectancy}

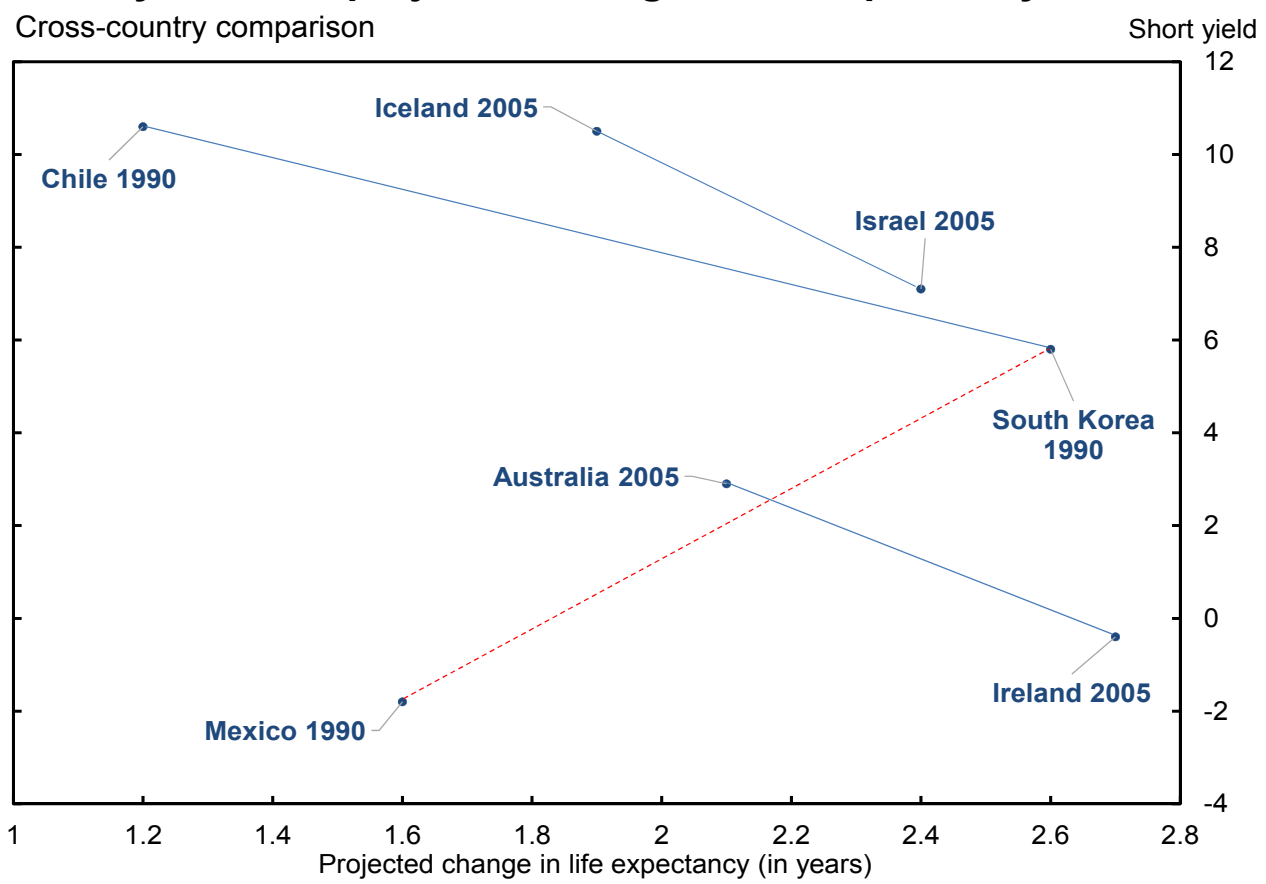

Figure 9: Country-pairs comparison of short-term real rates and projected changes in life expectancy.

rates might be discernible in the data. However, the exceptions illustrate the challenges in determining empirically the overall impact of demographics on real interest rates. For some of the pairs that we presented, the differences in country-specific factors are so obvious that introspection should suffice to conclude that several other elements must matter for our analysis. But even for pairs of countries that may "look alike," omitted variables are likely to play a role. For example, the comparisons depicted in Figures 8 and 9 abstract from other macroeconomic factors, such as countries' indebtedness, credit ratings, productivity growth, etc. An unconditional analysis has little chance to reach a clearcut conclusion on the links between demographics and real interest rates. Despite these challenges, the anecdotal evidence suggests that some of the patterns implied by the model might be discernible in simple cross-country comparisons. This consideration suggests a potentially fruitful avenue for future empirical research on this question. ${ }^{20}$

\section{$5 \quad$ Policy Implications}

An environment with a permanently low equilibrium real interest rate poses a challenge to the traditional approach to macroeconomic stabilization. This consideration should lead policymakers to

\footnotetext{
${ }^{20}$ Favero et al. (2014) show that demographics can account for the common persistent component of the term structure of nominal interest rates in the United States, while Juselius and Takats (2015) provide evidence that demographics and inflation are systematically correlated. Aksoy et al. (2015) use a panel VAR to study the effects of demographics on macroeconomic variables, and find that variation in the age profiles across OECD countries has economically and statistically significant impact on output growth, real interest rates, and inflation.
} 
reconsider the appropriate mix of monetary and fiscal interventions, as well as to entertain the possibility of using other policy instruments, either directly for stabilization or to counteract the downward pressure on real interest rates and create more room for monetary policy actions. In this section, we discuss some of these issues, keeping in mind that other factors besides demographics can push the equilibrium real interest rate to low levels - and possibly into negative territory. ${ }^{21}$

\subsection{Monetary Policy}

A low and declining equilibrium real interest rate carries two important implications for monetary policy. First, as discussed, for instance, by Ball (2013) and Krugman (2014), central banks may be forced to reconsider their inflation targets. ${ }^{22}$ In a world where the average equilibrium real interest rate is $2 \%$, a $2 \%$ inflation target implies an average nominal interest rate of $4 \%$. If, however, the equilibrium real interest rate falls to zero, perhaps due a combination of demographic trends and other forces, the resulting average nominal interest rate now becomes $2 \%$. All of a sudden, the room for central banks to respond to recessionary shocks has shrunk considerably. And this type of large shocks may actually be more frequent than previously thought, as the recent financial crisis has painfully demonstrated. A natural approach to counter this undesirable side-effect of the demographic transition on monetary policy is to raise the inflation target. However, the benefits of higher inflation must be weighted against its welfare costs, such as those stemming from higher price dispersion (e.g., Ascari and Sbordone 2014), and the distributional effects (Doepke and Schneider, 2006).

A second implication is perhaps slightly more subtle. In the baseline three-equation New Keynesian model (Clarida et al., 1999; Woodford, 2003), optimal monetary policy requires the nominal interest rate to track at each point in time the so-called "natural real interest rate." While specific details may vary, this result generalizes to most frameworks with nominal rigidities. In this class of models, the natural real interest rate is the real interest rate that would prevail absent nominal rigidities and markup shocks - that is, the real interest rate that arises in a frictionless environment. In the baseline model, the natural real interest rate is a combination of technology and preference shocks. In larger frameworks, other exogenous disturbances, such as investment-specific technology shocks, also show up in its expression.

The aforementioned structural shocks are typically assumed to be stationary. However, the demographic transition induces changes in the level of the natural real interest rate that are instead likely to be permanent - especially those associated with the increase in life expectancy. The central bank needs to take into account these permanent developments. ${ }^{23}$ Carvalho and Ferrero (2014) explore this connection between demographic developments and monetary policy to propose an explanation for the persistence of deflation in Japan, using the same framework as in this paper augmented with

\footnotetext{
${ }^{21}$ We conduct all the experiments of this section in the baseline version of the model. Because the real interest rate falls a lot more in the final steady state of the model with social security, all the numbers that we obtain from the comparative static exercises would be magnified in that context.

${ }^{22}$ See De Michelis and Iacoviello (2015) for an analysis of the Japanese experience with an increase of the inflation target.

${ }^{23}$ Fujiwara and Teranishi (2008) study how the dynamic response of a monetary economy to shocks changes around steady states with different demographic structures. Kantur (2013) explores how aging affects the effectiveness of monetary policy.
} 


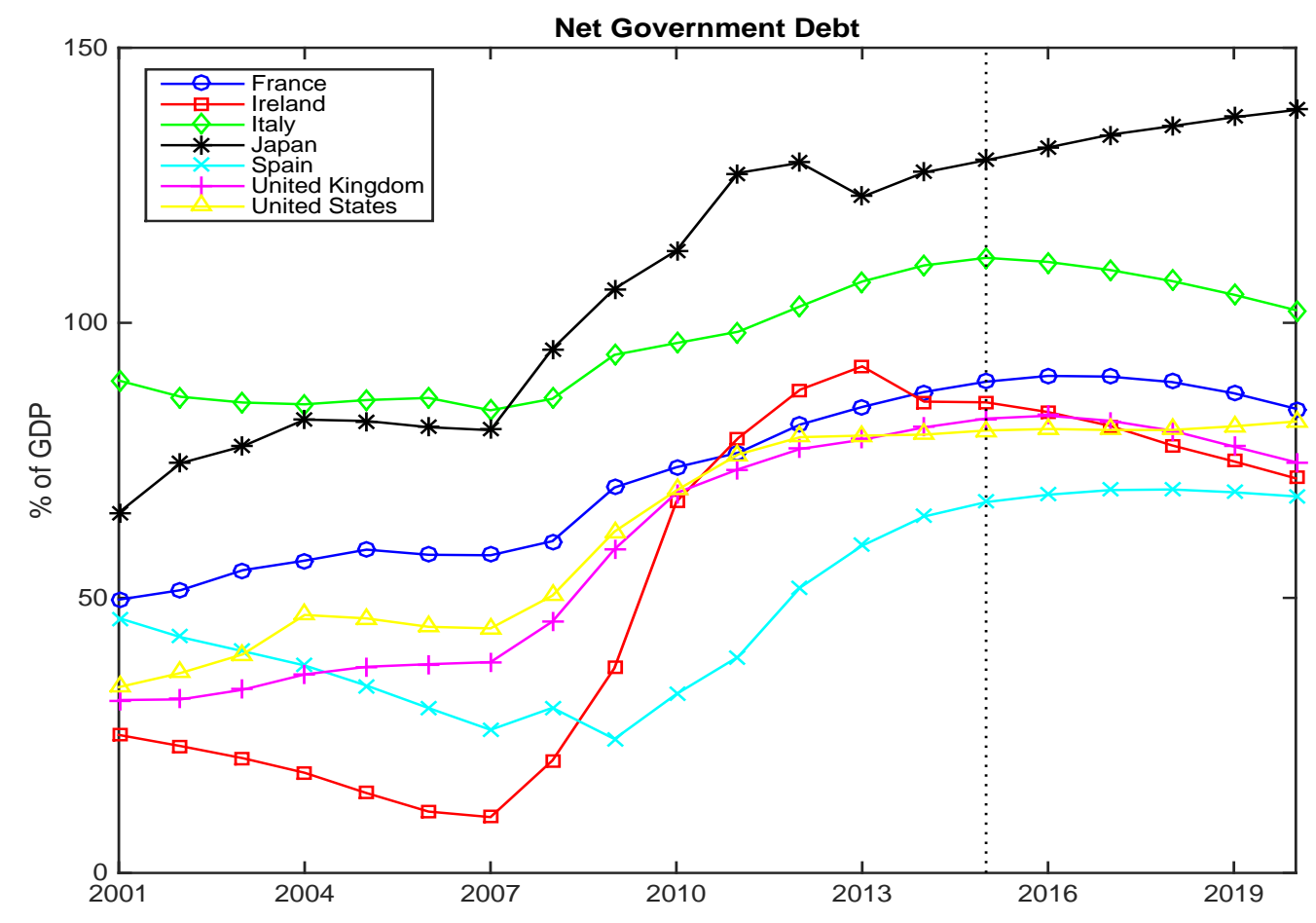

Figure 10: Ratio of net government debt to GDP. Sample: France (blue line with circles), Ireland (red line with squares), Italy (green line with diamonds), Japan (black line with stars), Spain (cyan line with x-marks), United Kingdom (magenta line with crosses), and United States (yellow line with triangles). Source: IMF World Economic Outlook Database April 2015.

nominal rigidities. Their calibration to the Japanese demographic transition induces a fall in the natural real interest rate of two to three percentage points between 1990 and 2014. If the central bank fails to adjust the nominal interest rate to the low frequency movements in the natural real interest rate induced by demographics, monetary policy is systematically too tight, and deflation arises in equilibrium. Quantitatively, the model can account for the persistence of Japanese deflation since the early 1990s.

\subsection{Fiscal Policy}

Whether to bailout banks or to provide economic stimulus (or both), governments of several advanced and emerging market economies responded to the GFC with expansionary fiscal policies. As a consequence, current levels and projected paths of public debt relative to GDP have notably shifted upward and are projected to remain high for the next few years (Figure 10). Should this increase in debt become permanent, this policy would - perhaps unintentionally - counterbalance some of the effects of the demographic transition on real rates. For example, Summers (2014) has recently advocated debtfinanced spending, pushing the idea that, in a Secular Stagnation environment, government demand can substitute for private demand. 
We can use our model to find the increase in the level of debt to GDP required to undo the effects demographics on the equilibrium real interest rate. In the final steady state of our baseline simulations, the real interest rate stabilizes around $2 \%$. The comparative statics exercise involves keeping the ratio of government spending to GDP at $20 \%$, and finding the level of debt to GDP that brings the real interest rate back to $4 \%$. In our calibrated model, the debt-to-GDP ratio can reach $210 \%$ before the real interest rate returns to $4 \%$.

Our calculations are arguably an upper bound on the required debt expansion, because the simulations do not take into account the increase in risk premia that are typically associated with large increases in government indebtedness, as the recent experience in the European periphery suggests. At the same time, however, the model returns a value of debt to GDP that is not too far from the levels currently observed in Japan - a country where the consequences of high levels of debt for risk premia appear to be very modest, but where the effects of the demographic transition are most visible.

\subsection{Structural Reforms}

This section considers two types of "structural reforms" that can contribute to directly increase the equilibrium real interest rate. The first is an unspecified reform that increases the growth rate of productivity — which is a parameter in the model. The second is an increase in the (average) retirement age, which is also controlled by a parameter in the model - the probability of retirement.

So far, in our simulations, we have kept the value of productivity growth fixed at $1 \%$. This number is actually on the high side for the largest advanced economies in the world. Recently, the literature has been debating to which extent the Secular Stagnation hypothesis could also involve a supply-side element. For example, Gordon (2012) suggests that the period between 1750 and 2000 may have been unique in the history of economic growth, thanks to several inventions that dramatically changed the global environment. Subsequent work by the same author (Gordon, 2014) forecasts real output per capita to grow at $0.9 \%$ over the next thirty years. ${ }^{24}$

Similarly to what we have done for fiscal policy, we can use the model to find the level of productivity growth rate that would restore a $4 \%$ real interest rate, starting from a steady state in which the demographic transition has completed its course. Interestingly, the answer is that a growth rate of $2 \%$ (up from 1\%) would be enough to raise the real interest rate by about two percentage points. ${ }^{25}$ This result has two sides to it. On the "comforting" side, the increase in productivity growth necessary to counteract demographic (and other) forces that put downward pressure on the real interest rate is not massive. Indeed, it would be enough to go back to growth rates that prevailed not so long ago. However, on the negative side, one worrying argument is that productivity slowdowns often occur after deep crises. After all, the Secular Stagnation idea originated after the Great Depression. Together with (and perhaps because of) the financial crisis, Japan has experienced a dramatic slowdown in productivity growth since 1990 (Hayashi and Prescott, 2002). Today, the global economy is still living through the consequences of the GFC. The study of possible interactions between persistent lack of demand and a technological slowdown seems more timely than ever.

\footnotetext{
${ }^{24}$ Needless to say, this view is far from representing any form of consensus (see, for example, Brynjolfsson and McAfee, 2014, for an opposite perspective).

${ }^{25}$ Among other factors, the results could be sensitive to changes in the elasticity of intertemporal substitution.
} 
Table 2: Retirement age by sex among OECD economies. Source: OECD (2010).

\begin{tabular}{|c|c|c|c|c|}
\hline Country & Male & Female & About to change? & Note \\
\hline Australia & 65 & 63 & Yes & Raised to 65 by 2014 for women; Both sexes to 67 in stages between 2017 and 2023 \\
\hline Austria & 65 & 60 & No & \\
\hline Belgium & 65 & 65 & No & \\
\hline Canada & 65 & 65 & No & Early pension can be claimed from age 60 \\
\hline Chile & 65 & 60 & No & \\
\hline Czech Republic & 62 & 61 & Yes & Increased to 63 for men from 2016 and for women without children from $2019^{*}$ \\
\hline Denmark & 65 & 65 & Yes & Proposal to raise to 67 over eight years starting in 2017 \\
\hline Finland & 63 & 63 & No & Can be up to age 68 \\
\hline France & 60 & 60 & Yes & Raised to 62 by 2018 \\
\hline Germany & 65 & 65 & Yes & Raised to 67 between 2012 and 2029 \\
\hline Greece & 65 & 60 & Yes & Plans to increase to 65 for women \\
\hline Hungary & 62 & 62 & Yes & Increase to 65 for men from 2018 and for women from 2020 \\
\hline Iceland & 65 & 65 & No & Private sector is 67 \\
\hline Ireland & 65 & 65 & No & No fixed age for private employees \\
\hline Italy & 65 & 60 & No & \\
\hline Japan & 60 & 60 & Yes & Gradually raised to 65 between 2001 and 2013 for men and 2006 and 2018 for women \\
\hline Korea & 60 & 60 & Yes & Will gradually reach 65 by 2023 \\
\hline Luxembourg & 60 & 60 & No & Retirement at 57 is possible \\
\hline Mexico & 65 & 65 & No & Early retirement available at 60 \\
\hline Netherlands & 65 & 65 & No & Plans to increase to 67 \\
\hline New Zealand & 65 & 65 & No & \\
\hline Norway & 67 & 67 & No & $60 \%$ of employees are entitled to early retirement at 62 \\
\hline Poland & 65 & 60 & No & Teachers and army forces entitled to early retirement \\
\hline Portugal & 65 & 65 & No & Early retirement possible from age 55 in some circumstances \\
\hline Slovakia & 62 & 57 & Yes & Increase to 62 for women by 2014 \\
\hline Spain & 65 & 65 & No & \\
\hline Sweden & 61 & 61 & No & Flexible, state pensions can be claimed starting at 61 \\
\hline Switzerland & 65 & 64 & No & \\
\hline Turkey & 60 & 58 & Yes & Plans to increase to 65 by 2035 for both sexes \\
\hline United Kingdom & 65 & 60 & Yes & Plans to increase to 65 over $2010-2020$ for women ${ }^{\dagger}$ \\
\hline United States & 66 & 66 & Yes & Increasing to 67 in stages \\
\hline
\end{tabular}

The second policy that we consider is the possibility that, in response to the demographic transition, the government increases the retirement age. Table 2 shows that several countries in the world are currently taking steps in this direction. In most cases, the increase in the retirement age is meant to address fiscal problems (unsustainable public pension systems). But the demographic transition is often the deep cause of such fiscal imbalances. As life expectancy increases, social security agencies need to pay pensions to individuals for a longer period of time. Obviously, this problem is particularly severe in defined-benefit systems of advanced economies, where shrinking generations of workers are responsible for the pensions of larger pools of retirees.

We assume that the government increases the retirement age by manipulating the probability of retirement $\omega$, and we perform a comparative static exercise similar to the ones for fiscal policy and productivity. An increase of two years in the retirement age - a typical reform currently being implemented in advanced economies - leads to a rather modest rise (10 basis points) in the real interest rate. Conversely, the reform that fully offsets the decline in the real interest rate due to the demographic transition would be enormous, requiring an average employment period of 107 years.

Our formulation of the population dynamics in the model makes labor force growth independent of the probability of retirement (equation 1). Here, we consider an alternative specification according to which increases in the (average) retirement age also lead to an increase in the growth rate of the labor force: 26

$$
N_{t}^{w}=\left(1+n_{t}\right) N_{t-1}^{w}-\left(1-\omega_{t}\right) N_{t-1}^{w}=\left(n_{t}+\omega_{t}\right) N_{t-1}^{w},
$$

where now $n_{t}$ corresponds to the rate of entry into the labor force, and labor force growth is given by $n_{t}+\omega_{t}$.

\footnotetext{
${ }^{26}$ Thanks to our discussant, Michael Krause, for suggesting this specification.
} 


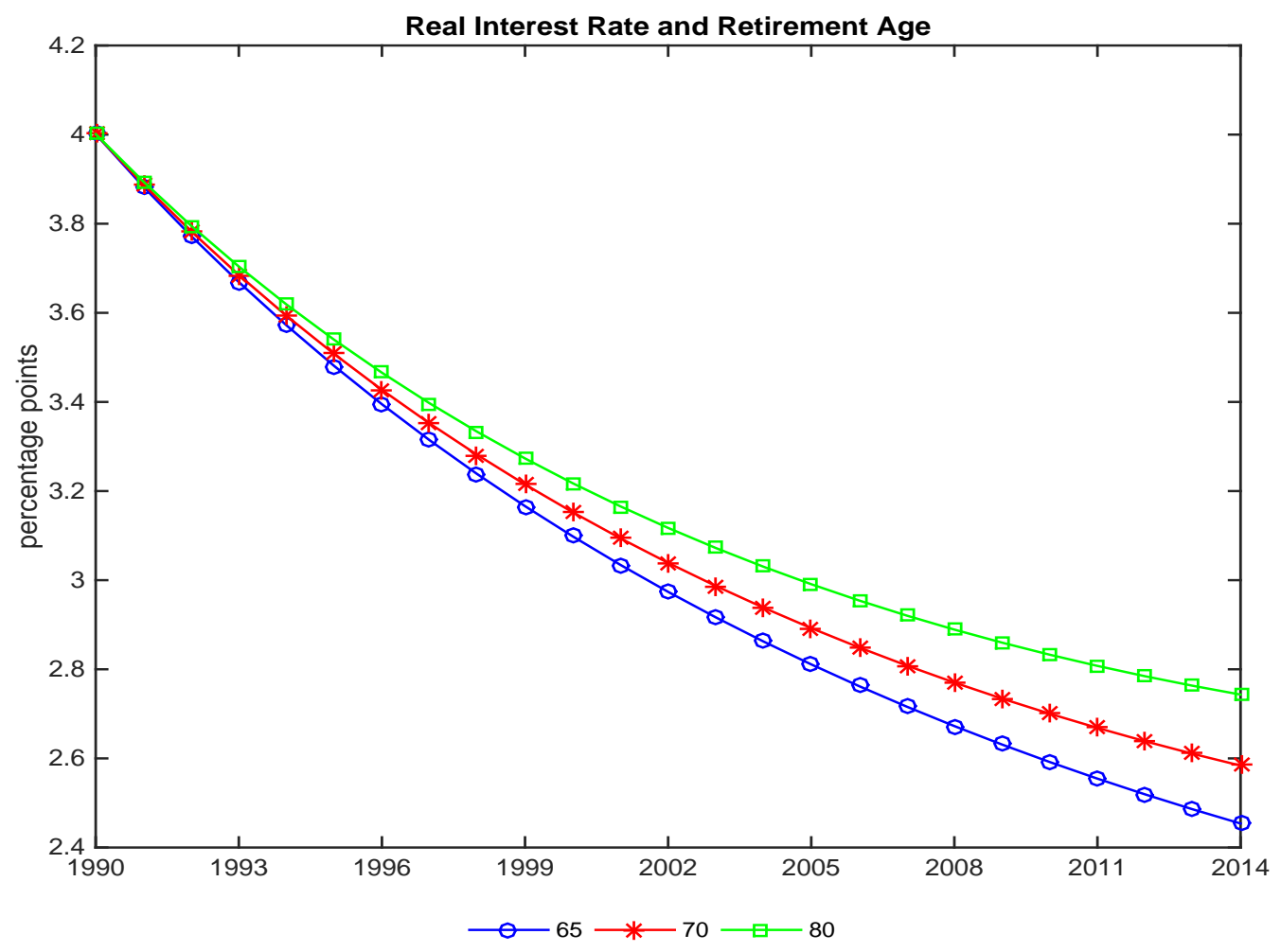

Figure 11: Simulated real interest rate following the full demographic transition with retirement probability indexed to the probability of surviving as in (20). Average retirement age in the final steady state of 65 (blue line with circles), 70 (red line with stars), and 80 (green line with squares).

Given our calibration strategy, the two specifications for population dynamics yield the same results for any given constant retirement probability $\omega$. The reason is that, as described in Section 3.1, we calibrate the path of $n_{t}$ to match data on population growth, the path of the survival probability $\gamma_{t}$ to match the dependency ratio, and the discount factor $\beta$ to match the real interest rate in the initial steady state. However, the two specifications lead to different comparative statics with respect to the retirement probability. When we redo our policy experiment with this alternative specification, we find that an increase of two years in the (average) retirement age has a larger, but still small in absolute terms, effect on the real interest rate (20 as opposed to 10 basis points under the baseline formulation). Similarly, the reform that fully offsets the decline in the real interest rate due to the demographic transition still requires a large increase in the average retirement age (76 years old), although significantly smaller than under the baseline formulation. The bottom line is that the policy implications remain essentially the same under the two specifications of population dynamics.

A more sensible implementation of reforms that seek to delay the transition into retirement would consist of indexing the retirement age to life expectancy, perhaps through periodic revisions. In the context of our model, a simple indexing scheme would be:

$$
\omega_{t}=\omega+\iota\left(\gamma_{t} / \gamma_{1990}-1\right)
$$


where $\iota$ determines the sensitivity of the retirement age to the increase in life expectancy (literally, the probability of surviving). For simplicity, we assume that the indexing occurs in every period, but the results would be unchanged if the revisions were periodic.

Figure 11 compares the baseline evolution of the real interest rate under the demographic transition with two indexing schemes in which retirement in the final steady state occurs, on average, at 70 and 80 years old, respectively. The reform limits the fall in the real interest rate. But, quantitatively, even the steeper indexing scheme has a limited impact. The real interest rate still falls by a comparable amount to the baseline decline (about 1.3 versus 1.5 percentage points).

While the exact quantitative implication of this experiment may depend on the details of the model, the overall message of these exercises is clear. Structural reforms that increase the retirement age go in the right direction to compensate the negative effects of the demographic transition on the real interest rate. Yet, if these policies are used in isolation, their effectiveness is likely to be small for reasonable changes from current conditions.

\section{Conclusion}

Demographic developments that most advanced economies are undergoing are a natural explanation for the prolonged decline of global real interest rates. The main channel through which demographics affect the real interest rate is the increase in life expectancy. At all stages of their life cycle, individuals save more to finance consumption over a longer time horizon. In our calibrated model, the demographic transition can account for about one third to a half of the overall decline in the real interest rate since 1990. We have provided some anecdotal evidence that the data support the importance of this channel, and discussed several policy implications.

Going forward, our research agenda on this topic consists of fully exploring the empirical dimension of this question, revisiting historical episodes of the connection between low interest rates and demographic changes, and studying its political economy consequences. 


\section{References}

Acemoglu, D. and S. Johnson (2007). Disease and Development: The Effect of Life Expectancy on Economic Growth. Journal of Political Economy 115, 925-985.

Aksoy, Y., H. Basso, R. Smith, and T. Grasl (2015). Demographic Structure and Macroeconomic Trends. Unpublished, Birkbeck College.

Ascari, G. and A. M. Sbordone (2014). The Macroeconomics of Trend Inflation. Journal of Economic Literature 52, 679-739.

Ball, L. (2013). The Case For Four Percent Inflation. Central Bank Review 13, 17-31.

Blanchard, O. (1985). Debt, Deficits and Finite Horizons. Journal of Political Economy 93, 223-247.

Brynjolfsson, E. and A. McAfee (2014). The Second Age Machine. Norton. New York, NY.

Carvalho, C. and A. Ferrero (2014). What Explains Japan's Persistent Deflation? Unpublished, PUC-Rio.

Chen, K., A. Imrohoroglu, and S. Imrohoroglu (2009). A Quantitative Assessment of the Decline in the U.S. Current Account. Journal of Monetary Economics 56, 1135-1147.

Clarida, R., J. Galí, and M. Gertler (1999). The Science of Monetary Policy: A New Keynesian Perspective. Journal of Economic Literature 37, 1661-1707.

De Michelis, A. and M. Iacoviello (2015). Raising an Inflation Target: The Japanese Experience with Abenomics. Unpublished, Board of Governors of the Federal Reserve System.

Doepke, M. and M. Schneider (2006). Inflation and the Redistribution of Nominal Wealth. Journal of Political Economy 114, 1069-1097.

Eggertsson, G. and N. Mehrotra (2014). A Model of Secular Stagnation. NBER Working Paper 20574.

Epstein, L. and S. Zin (1989). Substitution, Risk Aversion, and the Temporal Behavior of Consumption and Asset Returns: A Theoretical Framework. Econometrica 57, 937-969.

Erfurth, P. and C. Goodhart (2014). Demography and Economics: Look Past the Past. VoxEU.org.

Farmer, R. (1990). Rince Preferences. Quarterly Journal of Economics 105, 43-60.

Favero, C., A. Gozluklu, and H. Yang (2014). Demographics and the Behavior of Interest Rates. Mimeo, Bocconi University.

Ferrero, A. (2010). A Structural Decomposition of the U.S. Trade Balance: Productivity, Demographics and Fiscal Policy. Journal of Monetary Economics 57, 478-490.

Fujita, S. and I. Fujiwara (2014). Aging and Deflation: Japanese Experience. Federal Reserve Bank of Philadelphia. 
Fujiwara, I. and Y. Teranishi (2008). A Dynamic New Keynesian Life-Cycle Model: Societal Aging, Demographics, and Monetary Policy. Journal of Economic Dynamics and Control 32, 2398-2427.

Gertler, M. (1999). Government Debt and Social Security in a Life-Cycle Economy. Carnegie-Rochester Conference Series on Public Policy 50, 61-110.

Gordon, R. (2012). Is U.S. Economic Growth Over? Faltering Innovation Confronts the Six Headwinds. NBER Working Paper 18315.

Gordon, R. (2014). The Demise of U.S. Economic Growth: Restatement, Rebuttal, and Reflections. NBER Working Paper 19895.

Hall, R. (1988). Intertemporal Substitution in Consumption. Journal of Political Economy 96, 339-57.

Hamilton, J., E. Harris, J. Hatzius, and K. West (2015). The Equilibrium Real Funds Rate: Past, Present and Future. NBER Working Paper 21476.

Hansen, A. (1939). Economic Progress and Declining Population Growth. American Economic Review 29, 1-15.

Hayashi, F. and E. Prescott (2002). The 1990s in Japan: A Lost Decade. Review of Economic Dynamics 5, 206-235.

Juselius, M. and E. Takats (2015). Can Demography Affect Inflation and Monetary Policy? BIS Working Papers 485.

Kantur, Z. (2013). Aging and Monetary Policy. Unpublished, Bilkent University.

Karabarbounis, L. and B. Neiman (2014). The Global Decline of the Labor Share. Quarterly Journal of Economics 129, 61-103.

Kreps, D. and E. Porteus (1978). Temporal Resolution of Uncertainty and Dynamic Choice Theory. Econometrica 46, 185-200.

Krugman, P. (2014). Four Observations on Secular Stagnation. In Secular Stagnation: Facts, Causes and Cures, Chapter 4, pp. 61-68. VoxEU.org.

Nishimura, K. (2011). Population Ageing, Macroeconomic Crisis and Policy Challenges. Panel at the $75^{\text {th }}$ Anniversary Conference of Keynes' General Theory. University of Cambridge, UK.

Obstfeld, M. and K. Rogoff (1996). Foundations of International Macroeconomics. MIT Press. Cambridge, MA.

Rachel, L. and T. Smith (2015). Secular Drivers of the Global Real Interest Rate. Bank of England Working Paper 571.

Summers, L. H. (2014). Reflections on the New Secular Stagnation Hypothesis. In Secular Stagnation: Facts, Causes and Cures, Chapter 1, pp. 27-38. VoxEU.org. 
Woodford, M. (2003). Interest and Prices: Foundations of a Theory of Monetary Policy. Princeton University Press. Princeton, NJ.

Yaari, M. (1965). Uncertain Lifetime, Life Insurance, and the Theory of the Consumer. Review of Economic Studies 32, 137-150.

Yogo, M. (2004). Estimating the Elasticity of Intertemporal Substitution When Instruments Are Weak. Review of Economics and Statistics 86, 797-810. 